\title{
The Disease Protein Tulp1 Is Essential for Periactive Zone Endocytosis in Photoreceptor Ribbon Synapses
}

\author{
Silke Wahl, ${ }^{1 \star}$ Venkat Giri Magupalli, ${ }^{1 \star}$ Mayur Dembla, ${ }^{1 \star}$ Rashmi Katiyar, ${ }^{1 \star}$ Karin Schwarz, ${ }^{1 \star ~}$ [Louise Köblitz, ${ }^{1}$ \\ Kannan Alpadi, ${ }^{1}$ Elmar Krause, ${ }^{2}$ Jens Rettig, ${ }^{2}$ Ching-Hwa Sung, ${ }^{3}{ }^{\circledR}$ Andrew F. X. Goldberg, ${ }^{4}$ and ${ }^{\circledR}$ Frank Schmitz ${ }^{1}$ \\ ${ }^{1}$ Institute for Anatomy and Cell Biology, Department of Neuroanatomy, Saarland University, Medical School Homburg/Saar, 66421 Homburg/Saar, \\ Germany, ${ }^{2}$ Institute of Physiology, Saarland University, Medical School Homburg/Saar, 66421 Homburg/Saar, Germany, ${ }^{3}$ Margaret M. Dyson Vision \\ Research Institute, Department of Ophthalmology, Cell and Developmental Biology, Weill Medical College of Cornell University, New York, New York \\ 10021, and ${ }^{4}$ Eye Research Institute, Oakland University, Rochester, Michigan 48309
}

Mutations in the Tulp1 gene cause severe, early-onset retinitis pigmentosa (RP14) in humans. In the retina, Tulp1 is mainly expressed in photoreceptors that use ribbon synapses to communicate with the inner retina. In the present study, we demonstrate that Tulp1 is highly enriched in the periactive zone of photoreceptor presynaptic terminals where Tulp1 colocalizes with major endocytic proteins close to the synaptic ribbon. Analyses of Tulp1 knock-out mice demonstrate that Tulp1 is essential to keep endocytic proteins enriched at the periactive zone and to maintain high levels of endocytic activity close to the synaptic ribbon. Moreover, we have discovered a novel interaction between Tulp1 and the synaptic ribbon protein RIBEYE, which is important to maintain synaptic ribbon integrity. The current findings suggest a new model for Tulp1-mediated localization of the endocytic machinery at the periactive zone of ribbon synapses and offer a new rationale and mechanism for vision loss associated with genetic defects in Tulp1.

Key words: endocytosis; periactive zone; photoreceptor synapse; ribbon synapse; RIBEYE; Tulp1

Significance Statement

Mutations in the Tulp1 gene cause severe, early-onset retinitis pigmentosa (RP14) and Leber congenital amaurosis (LCA15) in human patients. In this study, we discovered that the phosphoinositol-4,5-bisphosphate-binding protein Tulp1 is essential for the structural and functional organization of the periactive zone in photoreceptor synapses. Using Tulp1 knock-out mice, we found that Tulp 1 is required to enrich major endocytic proteins at the periactive zone next to the synaptic ribbon. We demonstrate that Tulp1 is needed to promote endocytic vesicle retrieval at the periactive zone. Moreover, we discovered a novel interaction between Tulp1 and the synaptic ribbon protein RIBEYE. This newly discovered disease-sensitive interaction provides a molecular model for the control of endocytosis close to the synaptic ribbon.

\section{Introduction}

Retinitis pigmentosa (RP) and Leber congenital amaurosis (LCA) are severe inherited diseases of the retina caused by mutations in a variety of genes. Mutations in the Tulp1 gene are found

Received June 13, 2015; revised Dec. 21, 2015; accepted Jan. 19, 2016.

Author contributions: F.S. designed research; S.W., V.G.M., M.D., R.K., K.S., L.K., K.A., and F.S. performed research; E.K., J.R., C.-H.S., and A.F.X.G. contributed unpublished reagents/analytic tools; S.W., V.G.M., M.D., R.K., K.S., L.K., K.A., E.K., J.R., C.-H.S., A.F.X.G., and F.S. analyzed data; S.W., V.G.M., and F.S. wrote the paper.

This work was supported by National Institutes of Health Grants EY11307 and EY016805 to C.-H.S. and Grant EY013246 to A.F.X.G. and by German Research Community SFB TPP1 to E.K., SFB894 TPA10 GRK1326 to J.R., and SFB 894, TPA7 (Graduiertenkolleg GRK 1326) to F.S. We thank Prof. Dr. M. Biel (LMU Munich, Department of Pharmacy, Munich, Germany) and Prof. Dr. V. Flockerzi (Pharmacology Homburg) for Cav.1.4 knock-out tissue; and Dr. Varsha Pattu for help with the SR-SIM microscope.

The authors declare no competing financial interests.

*S.W., V.G.M., M.D., R.K., and K.S. contributed equally to this study.

Correspondence should be addressed to Dr. Frank Schmitz, Saarland University, Institute of Anatomy and Cell

Biology, Department of Neuroanatomy, 66421 Homburg/Saar, Germany; E-mail: frank.schmitz@uks.eu.

S. Wahl's current address: Knappschaftskrankenhaus Augenklinik, 66280 Sulzbach/Saar, Germany. in $\sim 2 \%$ of early-onset, juvenile autosomal recessive RP patients (RP14) and LCA patients (LCA15) (Hanein et al., 2004; Daiger et al., 2007; den Hollander et al., 2007, 2008). Tulp1 belongs to the tubby family of proteins that include tubby, tubby-like protein (Tulp)1, Tulp2, and Tulp3 (Carroll et al., 2004; Mukhopadhyay and Jackson, 2011). These proteins contain a highly conserved carboxy terminal "tubby" domain of $\sim 250$ amino acids, which binds to phosphoinositol-4,5-bisphosphate $\left(\mathrm{PIP}_{2}\right)$ (Boggon et al., 1999; Santagata et al., 2001). Most disease-causing mutations

V.G. Magupalli's current address: Program in Cellular and Molecular Medicine, Boston Children's Hospital and Department of Biological Chemistry and Molecular Pharmacology, Harvard Medical School, Boston, Massachusetts 02115 .

L. Köblitz's current address: Biocrates Life Science, Innsbruck, Austria.

K. Alpadi's current address: Baylor College of Medicine, Department of Biochemistry and Molecular Biology, Houston, Texas 77030.

D0I:10.1523/JNEUROSCI.2275-15.2016

Copyright $\odot 2016$ the authors $\quad 0270-6474 / 16 / 362473-21 \$ 15.00 / 0$ 
in the Tulp1 gene are clustered in the tubby domain of Tulp1. In the retina, expression of Tulp1 is largely confined to photoreceptors (Ikeda et al., 1999, 2002; Kikuchi et al., 2000; Milam et al., 2000; Hagstrom et al., 2001; Grossman et al., 2009). Tulp1 is enriched in different photoreceptor compartments, including the presynaptic terminals. ERG analyses indicated early disturbances of synaptic transmission in Tulp1 knock-out $(-/-)$ mice (Xi et al., 2007; Grossman et al., 2009). But the synaptic function of Tulp1 and its precise localization in photoreceptor synapses remained unclear.

Photoreceptor ribbon synapses are specialized for continuous synaptic vesicle exocytosis (Matthews and Fuchs, 2010). A presynaptic specialization, the synaptic ribbon, appears to organize presynaptic vesicle trafficking at this synapse. The ribbon is associated with large numbers of synaptic vesicles and anchored at the active zone where L-type voltage-gated calcium channels are clustered. Synaptic vesicle exocytosis preferentially occurs at the active zone, at the base of the synaptic ribbon (Matthews and Fuchs, 2010). The periactive zone that surrounds the active zone and the synaptic ribbon has been shown to be an area of high endocytic activity, as judged by electron microscopy (Gray and Pease, 1971), high-resolution imaging and uptake assays (Wahl et al., 2013; Dembla et al., 2014), as well as by TIRF microscopy (Pelassa et al., 2014). Rod photoreceptor synapses have a single active zone to which a particularly large, plate-like synaptic ribbon is attached (Schmitz, 2009). Because of the invaginated shape of the presynaptic photoreceptor terminal and the active zone, photoreceptor synaptic ribbons typically adopt a horseshoeshaped appearance if visualized from side views (Schmitz, 2009). RIBEYE is a unique structural component of synaptic ribbons (Schmitz et al., 2000; Magupalli et al., 2008). It consists of a proline-rich, amino terminal A domain and a carboxy terminal B domain, which is largely identical with CtBP2 (Schmitz et al., 2000). The A domain of RIBEYE has multiple interaction sites for other RIBEYE molecules that enables RIBEYE to build a scaffold for the synaptic ribbon (Magupalli et al., 2008; Schmitz, 2009). The $\mathrm{B}$ domain is probably located on the surface of the ribbons where it can interact with proteins of the presynaptic terminal (Schmitz, 2009, 2014).

In the present study, we demonstrate that Tulp 1 is essential for the structural and functional maintenance of the endocytic machinery in the periactive zone of photoreceptor synapses. Furthermore, we demonstrate a novel interaction between Tulp1 and RIBEYE, which is affected by RP-causing mutations of Tulp1. These data propose Tulp1 as a central organizer of endocytic vesicle trafficking in the photoreceptor ribbon synapse.

\section{Materials and Methods}

\section{RIBEYE plasmids}

RIBEYE plasmids included the following: $R E(A B) p G B K T 7$, encoding full-length RIBEYE in pGBKT7 (Magupalli et al., 2008); RE(B)pGBKT7, encoding full-length RIBEYE(B) domain in pGBKT7 (Magupalli et al., 2008); RIBEYE(B)SBDpGBKT7, encoding the substrate-binding subdomain (SBD) of RIBEYE(B) in pGBKT7 (Magupalli et al., 2008); RIBEYE(B)NBDpGBKT7, encoding the $\mathrm{NAD}(\mathrm{H})$-binding subdomain (NBD) of RIBEYE(B) in pGBKT7 (Magupalli et al., 2008); RIBEYE(A) pGBKT7, encoding full-length RIBEYE A domain in pGBKT7 (Magupalli et al., 2008); RIBEYE(A)myc, encoding full-length RIBEYE A domain in pCMVmyc (Schmitz et al., 2000); and RE(B)myc-BIFCpCMV, encoding RIBEYE(B) domain in pNV2-myc. The insert was PCR amplified using the following primers TTTTTCTCGAGTATCCGCCCCCAGATCAT, TTT TTTCTAGACTATTGCTCGTTGGGGTG, and bovine RIBEYE(B) cDNA as template and cloned in frame into the XhoI/XbaI site of pNV2-myc (Ritter et al., 2011).

\section{Tulp1 plasmids}

Tulp1 plasmids included the following: Tulp1(352-546)pACT2 (yeast-twohybrid [YTH] prey clone \#1051), encoding amino acids 352-546 of bovine Tulp1, obtained with YTH screening using RIBEYE(B) as bait; Tulp1(292546)pACT2, encoding the tubby domain of Tulp1 in pACT2 (insert was amplified via PCR using the following primers: forward primer TTTGG ATCCTTGTGGAAGTG GACGAACCCCA, reverse primer TTTCTCGA GTCACTCGC AGGCCAGCTTCC, and bovine cDNA as template; the PCR product was cloned into the $\mathrm{BamHI} / \mathrm{Xhol}$ sites of $\mathrm{pACT} 2)$; and Tulp1(1-546)pACT2, encoding full-length Tulp1 in pACT2.

\section{Cloning of full-length bovine Tulp1 (bTulp1) cDNA}

The originally obtained YTH prey clone (clone 1051) covered amino acids 352-546 of bovine Tulp1 in frame with the activation domain of pACT2. Full-length Tulp1 cDNA was completed by PCR using bovine cDNA as a template. For PCR amplification of the cDNA of N-terminal region of Tulp1 that was not contained in the original prey clone, we used PCR and the following primers: AAACCATGGAAATGCCTCTGCG GGATGAACCCCTCCGAG (forward primer) and GGGCACCCTTT CGTTGT (reverse primer). Because the bovine cDNA of Tulp1 was initially unknown, the $5^{\prime}$ primer was designed based on the known human cDNA sequence of Tulp1 (GenBank accession BC065261). The resulting $\sim 1.2 \mathrm{~kb}$ PCR product was digested with $\mathrm{NcoI}$ and EcoRI and cloned into the respective sites of Tulp1 amino acids 352-546pACT2 to obtain fulllength Tulp1(1-546) in pACT2 (Tulp1(1-546)pACT2. The bovine $5^{\prime}-$ sequence was determined with a $5^{\prime}$-RACE reaction using the following primers: AGGGTGGCCAGAGAAGT (forward primer), CTCCTCCTC ATCCCCG (reverse primer), and bovine cDNA as template. The 5'RACE PCR product was cloned into TA vector and fully sequenced. The cDNA sequence of the ORF of bovine Tulp1 obtained by this way is identical to the GenBank database entry XM_865044).

Other Tulp1 plasmids are as follows: Tulp1R424PpACT2. The point mutant was generated as previously described (Alpadi et al., 2008; Magupalli et al., 2008) using the following primers: outward forward, TTTTCCATGGT TGTGGACGAACCCCAGG; outward reverse, TTTTCTCGAGTTTCA CTCG CAGGCCAGC; mutated forward, CCCCGGCCCATGACGGTC ATCATTCCTGG; mutated reverse, CATGGGCCGGGGACCTCGGAAG CCCAGGC; and Tulp1 cDNA as template. Tulp11463KpACT2. The point mutant was generated as previously described (Alpadi et al., 2008; Magupalli et al., 2008) using the following primers: outward forward, TTTTCCATG GTTGTGGACGAACCCCAGG; outward reverse, TTTTCTCGAGTT TCACTCG CAGGCCAGC; mutated forward, AGCCTCAAGGAGCTGC ACAACAAGCCCCCCAT; mutated reverse, CAGCTCCTTGAGGC TCTCCAGTGTCTTGTTCTG; and Tulp1 cDNA as template. Tulp1 K493RpACT2. The point mutant was generated as previously described (Alpadi et al., 2008; Magupalli et al., 2008) using the following primers: outward forward, TTTTCCATGGTTGTGGACGAACCCCAGG; outward reverse, TTTTCTCGAGTTTCACTCGCAGGCCAGC; mutated forward, TCAGTCAGAAATTTCCAGATTGTCCACGTCGATGAC; mutated reverse, CTGGAAATTTCTGACTGAGGCCTGGGTGACTCG; and Tulp1 cDNA as template. Tulp1F495LpACT2. The point mutant was generated as previously described (Alpadi et al., 2008; Magupalli et al., 2008) using the following primers: outward forward, TTTTCCATGGTTGTGGACGAACCCCAGG; outward reverse, TTTTCTCGAGTTTCACTCGCAGGCCAGC; mutated forward, AATTTACAGATTGTCCACGCTGATGACCCCG; mutated reverse, GACAATCTGTAAATTCTTGACTGAGGCCTGG; and Tulp1 cDNA as template. Tulp1 $\triangle 503-546 p A C T 2$. The carboxy terminal deletion mutant was generated by PCR using forward primer TTTTCCATGGTTGTGGACGA ACCCCAGG, reverse primer TTTTCTCGAGTGTCATCAGCGTGGACAAT, Tulp1 cDNA as template, and cloned into the NcoI/XhoI sites of pACT2. Tul$p H A-B I F C p C M V$. TulpHA-BIFCPCMV, encoding the tubby domain of Tulp1 in pNV1-HA. The insert was PCR-amplified using the following primers: TTTTTCTCGAGTGTGGACGAACCCCAGG, TTTTTTCTAGATCACTCGCAGGCCAGCT, the tubby domain of bovine Tulp1 as template, and cloned in frame into the XhoI/XbaI sites of pNV1-HA (Ritter et al., 2011).

\section{Parental vectors and control plasmids}

Parental vectors and control plasmids are as follows: pGBKT7, pACT2; pSE1111, pSE1112 (Alpadi et al., 2008; Magupalli et al., 2008); pNV2- 
myc, empty myc-bimolecular fluorescence complementation assay (BIFC) vector (Ritter et al., 2011); and pCV1-HA, empty HA-BIFC vector (Ritter et al., 2011).

\section{Antibodies}

Antibodies against Tulp1. We generated monoclonal and polyclonal antibodies against Tulp1. The polyclonal antibody (T1N1) was generated against the 18 amino terminal amino acids of human Tulp1. This region is highly conserved between species (human, mouse, bovine Tulp1; GenBank entries NP 067453, CAI 20251, XM_865044). The monoclonal antibody (5G2-4) was generated against an internal peptide of bovine Tulp1 (amino acids 50-59: PTGSKPRRPG). The specificity of both antibodies for Tulp1 was verified by Western blot analyses with retinal extracts from Tulp1 knock-out and control mice (see Fig. 1). Both antibodies detected a single band at the expected running position of Tulp 1 of $\sim 60 \mathrm{kDa}$ in the wild-type retina, which was absent in the Tulp1 knock-out retina (see Fig. $1 A, B)$.

Antibodies against RIBEYE. Rabbit polyclonal antibodies (U2656) and mouse monoclonal antibodies against $\operatorname{RIBEYE}(\mathrm{B})$ domain were used as previously described (Schmitz et al., 2000; Magupalli et al., 2008; Wahl et al., 2013; Dembla et al., 2014). In some experiments, mouse monoclonal antibodies against RIBEYE(B) domain were directly labeled with Alexa650, as previously described (Wahl et al., 2013).

Antibodies against $\mathrm{PIP}_{2}$. A protein A-purified mouse monoclonal antibody against $\mathrm{PIP}_{2}$ was obtained from Abcam (ab2335). In addition to $\mathrm{PIP}_{2}$ labeling at the synapse (specificity confirmed by preabsorption analyses; data not shown), this antibody also produced some nonspecific staining of nuclei, which cannot be blocked by preabsorption with an excess of $\mathrm{PIP}_{2}$ and which was therefore not considered as relevant signal (data not shown). For immunofluorescence microscopy on $0.5-\mu \mathrm{m}$ thick resin sections, the $\mathrm{PIP}_{2}$ antibody was used in a 1:20 dilution.

Other antibodies included the following: antibodies against dynamin (hudy-1), mouse monoclonal (Wahl et al., 2013); antibodies against clathrin heavy chain, rabbit polyclonal (Wahl et al., 2013); anti-EEA1 (Abcam, ab2900, rabbit polyclonal); and anti- $\beta$-tubulin (Sigma, \#T0198, mouse monoclonal).

Anti-Cav1.4. Mouse monoclonal antibody (clone \#5F6) raised against the peptide MSESEVGKDTTPEPSPANGT from the amino terminus (amino acids 1-20) of mouse $\alpha 1 \mathrm{~F}$-subunit of voltage-gated channels (GenBank \#EDL33903.1). The cell culture supernatant was used at a 1:2 dilution for immunofluorescence microscopy. The specificity of this antibody for Cav1.4 was checked by immunolabeling Cav1.4 knock-out and control tissue (data not shown).

Anti-clathrin heavy chain. Mouse monoclonal antibody (clone \#7A9) raised against the peptide YFIQVMKEYLTKVDKLDASESLRK from the carboxy terminus (amino acids 1246-1269) of mouse clathrin heavy chain (GenBank \#15798.1) used at a 1:500 dilution for immunofluorescence microscopy. This mouse monoclonal antibody generated exactly the same periactive zone labeling as previously characterized polyclonal antibodies against clathrin heavy chain and perfectly overlapped with it. The antibody labeled a single protein band at the expected running position of $\sim 180 \mathrm{kDa}$ in Western blot analyses (data not shown).

Other antibodies included the following: anti-RIM1/2 (rabbit polyclonal antibody against RIM1/2 (Schoch et al., 2006; Anjum et al., 2014) used at a 1:500 dilution for immunofluorescence microscopy; anti-HA tag (Abcam, ab9110), a polyclonal rabbit antibody raised against the HA-epitope (YPYDVPDYA, conjugated to KLH); the antibody was used for immunofluorescence on fixed HEK293T-cells in a 1:10,000 dilution; anti-c-Myc (9E10) (Santa Cruz Biotechnology, sc-40), a mouse monoclonal antibody raised against amino acids 408-439 within the C-terminal domain of c-Myc of human origin. The antibody was used for immunofluorescence on fixed HEK293T-cells in a 1:1000 dilution.

\section{Secondary antibodies}

Secondary antibodies included the following: chicken anti-mouse immunoglobulins conjugated to Alexa-488 (Invitrogen, A21200); donkey anti-rabbit immunoglobulins conjugated to Alexa-568 (Invitrogen, A10042); goat anti-mouse immunoglobulins conjugated to Alexa-647 (Invitrogen, A21236); goat anti-rabbit peroxidase conjugate (Sigma, A6154); and goat anti-mouse peroxidase conjugate (Sigma, A3673).
Transfection of HEK293T cells. HEK293T cells were used for heterologous protein expression. Cells were split and plated on glass coverslips in 6 well dishes containing $1 \mathrm{ml}$ of DMEM (containing 10\% FCS). After $24 \mathrm{~h}$ of culture, HEK293T cells were transfected with the eukaryotic expression constructs using the Perfectin transfection kit from Genlantis, as described by the manufacturer. HEK293T cells were used both for colocalization experiments of heterologously expressed proteins as well as for BIFC analyses.

\section{Tulp1 knock-out mice}

Tulp1 knock-out mice (Ikeda et al., 1999) were obtained from The Jackson Laboratory (B6.129X1-Tulp $\left.{ }^{\mathrm{tm} 1 \mathrm{Pjn} / \mathrm{Pjn}}\right)$. The genotyping was done using a primer pair in exon 8 of the Tulp1 sequence for the wild-type reaction: 5'AAGGAGGAGAGAGCCTCTTC3' (forward) and 5'TTCTCAGTGTC CAGGTGCAG3' (reverse); and a pair of primers for the neo-cassette: 5'ACAATCGGCTGCTCTGA3' (forward) and 5'GTCACGACGAGAT CATC3' (reverse) for the knock-out reaction. A 167 bp PCR product was received for the wild-type and a $500 \mathrm{bp}$ PCR product for the knock-out. Animal care and all experimental procedures were performed in accordance with the guidelines established by the animal welfare committee of the Saarland University, School of Medicine. Mice of both sexes were used for experiments and were kept under standard light/dark cycle with food and water ad libitum.

\section{Immunolabeling of $0.5-\mu m$-thin retinal resin sections}

Immunolabeling of $0.5-\mu \mathrm{m}$-thin resin sections was performed exactly as previously described (Wahl et al., 2013; Dembla et al., 2014). It uses a PFA-free embedding/immunolabeling procedure that has low intrinsic background and can be performed on very thin sections to obtain high resolution. Immunolabeled sections were analyzed with a Zeiss Axiovert200 epifluorescence microscope (equipped with Axiovision software, version 4.8), an A1R-MP confocal microscope (Nikon) (equipped with NIS Elements software; AR 3.2 64bit), or an Elyra PS1 super-resolution microscope (Zeiss, equipped with ZEN software), as indicated in the respective experiments.

\section{Evaluation of changes in protein expression in photoreceptor} synapses of Tulp1 knock-out mice and littermate control mice We evaluated changes in the expression of synaptic proteins in photoreceptor synapses in the outer plexiform layer (OPL) of P16 old Tulp1 knock-out mice (compared with littermate control mice) by quantifying immunolabeled retinal resin sections. For the quantification analyses, $0.5-\mu \mathrm{m}$-thin retinal sections were double-immunolabeled with antibodies against RIBEYE (in channel 1) and the protein of interest (i.e., dynamin, clathrin heavy chain, RIM1/2; Cav1.4) (in channel 2), as described above. All immunolabeling steps were performed in parallel identically for slices of both genotypes (i.e., Tulp1 knock-out mice and littermate control mice; antibody dilutions, incubation times, temperature for both primary and secondary antibodies). From the immunolabeled retinal sections, images were acquired with an A1R confocal microscopy under identical conditions (laser power, gain, offset, contrast, gamma values) for both genotypes (Tulp1 knock-out and littermate control animals) by applying the "reuse image settings" option of the NIS elements software. Furthermore, the inner plexiform layer (IPL) of the retina provided an additional section-intrinsic control given the assumption that synaptic proteins are not altered in synaptic layers where Tulp1 is not expressed. For quantitative analyses, the 16 bit images obtained from confocal imaging with the A1R microscope were opened with ImageJ without any manipulation and split into the individual channels. In each fluorescence channel, signal intensity was measured with Image in the OPL and in the IPL (that was immunolabeled by RIBEYE) for both Tulp1 knock-out and littermate control mice at identical conditions. The immunosignals in the OPL were related to the immunosignals in the IPL where Tulp1 is not expressed. The immunosignals in the IPL therefore served as an additional control that documents equal image acquisition conditions for both knock-out and control samples. By this way, possible differences in signal intensities that are based on differences in section thickness were also corrected. Thus, the relative intensities given in Figure $5 E-G$ refer to the intensity ratio of the indicated protein in the OPL divided through the signal intensity in 
the IPL. Only for the Cav1.4 channels that are highly expressed in the OPL but only to a very minor extent in the IPL (Grabner et al., 2015), we plotted the absolute fluorescence intensity values (with the wild-type values set to $100 \%$ ) and not as a signal intensity ratio OPL to IPL. In all quantification analyses, the signal intensities of RIBEYE that represent the immunolabeled synaptic ribbons were virtually identical between knock-out and control samples at P16 (see Fig. 5E-H). Quantification of RIBEYE signals at P16 did not differ significantly between different trials (see Fig. $5 E-H$ ), emphasizing the reliability of the selected procedure. Also, proteins of the active zone (i.e., RIM, Cav1.4; see Fig. 5G,H) did not differ between Tulp1 control and knock-out mice, whereas endocytic proteins in the periactive zone showed a strong reduction in the OPL (see Fig. $5 E, F)$. Analyses of the immunolabeled sections were performed blindly with the reviewer not knowing whether the immunolabeled section is from knock-out or control animals.

\section{Determination of synaptic ribbon numbers in photoreceptor} synapses of the OPL

Synaptic ribbons were visualized by immunolabeling of $0.5-\mu \mathrm{m}$-thin retinal resin sections with antibodies against RIBEYE as described above. Single synaptic ribbons can be easily identified by this method (Wahl et al., 2013; Dembla et al., 2014) (see Figs. 2, 7, 9). Synaptic ribbons in photoreceptor synapses of the OPL were quantified with a Zeiss Axiovert200M microscope using a 100× Plan Fluar objective (NA 1.45) and RIBEYE-immunolabeled $0.5-\mu \mathrm{m}$-thin retinal sections of Tulp1 knock-out and littermate control mice. Measurements were done with the Axiovision software (version 4.8). Statistical analyses were performed with two-sided Student's $t$ tests.

\section{Quantification of colocalization in immunolabeled bovine retinal sections}

All immunostainings were performed under the same conditions, using antibodies at indicated dilutions. Fluorescent images of stained bovine retina were taken with the Axiovert 200M microscope from Zeiss. All pictures were taken under exactly the same conditions (same exposure times, same gamma values, same frame size of the camera, same magnification). Picture analyses was performed in a blinded fashion with the examiner not knowing which proteins were labeled in the individual experiments. Pictures were analyzed in ImageJ. For all experiments, each picture was opened in ImageJ and split in its individual channels using the "split chanel" command of the software. Colocalization analysis was performed for signals in the OPL using the "colocalization threshold" plugin of ImageJ, which relies on the Costes automatic thresholding method (Costes et al., 2004) to determine signal thresholds and to calculate the Manders' Colocalization Coefficients (Dunn et al., 2011). To obtain an overall thresholded Manders colocalization coefficient (tMCC) for each experimental set, individual tMCCs of individual sections were noted and averaged.

\section{Super-resolution structured-illumination microscopy (SR-SIM)}

SR-SIM microscopy was performed exactly as previously described (Wahl et al., 2013; Dembla et al., 2014). For structured illumination microscopy, an ELYRA PS1 microscope system from Zeiss was used. Images were taken with a $63 \times$ Plan-Apochromat $(\mathrm{NA}=1.4)$ with excitation laser light of 488,561 , and $635 \mathrm{~nm}$ wavelengths and then processed for structured illumination microscopy with the ZEN2010 software to obtain higher resolutions (Wahl et al., 2013; Dembla et al., 2014). The resolution of normal microscopy is limited to $\approx 200 \mathrm{~nm}$ in XY direction. SRM gives the possibility to exceed this diffraction limit. SR-SIM increases the lateral resolution by a factor of 2 (Schermelleh et al., 2010).

\section{Bimolecular fluorescence complementation (BIFC) analyses}

BIFC analyses for the assessment of Tulp 1/RIBEYE-interaction were performed exactly as previously described (Ritter et al., 2011) using an A1R-MP confocal microscope (Nikon). For BIFC assays, RIBEYE(B) domain and the tubby domain of Tulp1 were cloned into the respective BIFC expression vectors (see above). Each of the BIFC vectors encodes complementary parts of mVenus that do not bind to each other and are nonfluorescent without complementation. In the BIFC plasmids, the complementary parts of $\mathrm{mVenus}$ are fused in frame with the proteins of interest (i.e., Tulp1 and RIBEYE). If both parts of mVenus are recruited to each other via the protein-protein interaction of the attached proteins of interest, the mVenus fluorophore is reconstituted and emits its typical fluorescence, which is subsequently detected. The BIFC vectors are also equipped either with a myc-tag or with a HA-tag to verify expression of the different proteins independent from potential interaction. The HA signal was typical detected with secondary antibodies conjugated to Alexa-568, whereas the myc-tag was typically detected with secondary antibodies conjugated with Alexa-647. The BIFC signal was detected in the green channel in case of interaction.

In the present study, RIBEYE(B) was fused with the myc-tag and Tulp1 with an HA-tag. The RIBEYE(A)-Tulp1 interaction was analyzed by plain colocalization analyses in double-transfected HEK cells (Schmitz et al., 2000; Magupalli et al., 2008). At $24 \mathrm{~h}$ after transfection, cells were fixed with $1 \%$ PFA in PBS (10 min; room temperature). After several washes with PBS, cells were permeabilized for $15 \mathrm{~min}$ with $0.1 \%$ Triton $\mathrm{X}-100$ in PBS and treated for 30 min with blocking buffer, containing $0.1 \%$ Triton X-100, $0.5 \%$ BSA in PBS and further processed for immunolabeling.

As controls, experimental BIFC constructs (e.g., Tulp1, RIBEYE constructs) were transfected with the empty myc/HA-BIFC vectors to test for unspecific BIFC signals. Laser intensity was adjusted to a minimum (typically $<1 \%$ laser power) to make sure that no signal can leak into neighboring detection channels. To judge on fluorescence leaking into neighboring channel, the laser power of the respective laser was set to 0 , whereas the sensitivity settings of the detector were left unchanged. No crosstalk of fluorescence into neighboring channels (e.g., the BIFC channel) was observed under these conditions. Further controls included transfection with only one plasmid or cotransfection with empty or irrelevant plasmids.

\section{Immunofluorescence of transfected HEK293T cells/colocalization} analyses in cotransfected HEK293T cells

HEK293T cells were transfected as previously described (Schmitz et al., 2000; Magupalli et al., 2008) and fixed for 10 min with $1 \%$ PFA in PBS. After several washes in PBS, cells were permeabilized with $0.1 \%$ Triton X-100 in PBS (15 min, room temperature) and treated with PBS containing 0.5\% BSA ("blocking buffer") to block nonspecific protein binding sites. Primary antibodies were diluted with blocking buffer at the indicated dilutions overnight at $4^{\circ} \mathrm{C}$. Binding of the secondary antibodies was visualized by the indicated fluorophore-conjugated secondary antibodies.

\section{Isolation of photoreceptors}

Photoreceptor cells were isolated from the retinas of 16- to 18-d-old Tulp control and knock-out mice. Retinas were isolated within 5 min postmortem (in $\operatorname{dim}$ ambient light, $\approx 30 \mathrm{~cd} / \mathrm{m}^{2}$ ). The enucleated eyes were bisected at the equatorial plane, and the posterior eye cup transferred into low- $\mathrm{Ca}^{2+}$-containing saline solution (abbreviated as "LCS" solution, containing $132 \mathrm{~mm} \mathrm{NaCl}, 3 \mathrm{~mm} \mathrm{KCl}, 1 \mathrm{~mm} \mathrm{MgCl}_{2} \times 6 \mathrm{H}_{2} \mathrm{O}, 0.5 \mathrm{~mm}$ $\mathrm{CaCl}_{2}, 10 \mathrm{~mm}$ sodium pyruvate, $10 \mathrm{~mm}$ glucose, $10 \mathrm{~mm}$ HEPES, $\mathrm{pH}$ 7.4, $\approx 300 \mathrm{mOsm} / \mathrm{L}$ ). LCS was saturated with $5 \% \mathrm{CO}_{2} / 95 \% \mathrm{O}_{2}$ before use. The isolated posterior eyecup was kept at $37^{\circ} \mathrm{C}$ for $2 \mathrm{~h}$ in oxygenated LCS. From the posterior eyecup, the neural retina was gently peeled off from the pigment epithelium and incubated in $1 \mathrm{ml}$ of cysteine-activated papain solution [containing $9 \mathrm{U} / \mathrm{ml}$ papain (Sigma, \#76220-25G) and 2.7 mM L-cysteine (Roth, \#1693.1) in LCS] for $25 \mathrm{~min}$ at $25^{\circ} \mathrm{C}$. Activation of papain $(9 \mathrm{U} / \mathrm{ml})$ was done by preincubation with L-cysteine $(2.7 \mathrm{~mm}$ in LCS) at $37^{\circ} \mathrm{C}$ for $20 \mathrm{~min}$. After removing the papain solution, the retina was gently washed three times with $1 \mathrm{ml}$ of LCS solution containing $2 \%$ FCS and $0.01 \mathrm{mg} / \mathrm{ml}$ DNase (Sigma, \#DN25-110MG). To dissociate photoreceptor cells, papain-treated retina was very gently triturated (3-4 times) with a wide-bore plastic Pasteur pipette. The resulting cell suspension was plated on concanavalin A (\#C7275, Sigma)-coated coverslips (Wahl et al., 2013; Dembla et al., 2014). For immunocytochemistry, cells were washed once with LCS and fixed with ice-cold 4\% PFA in PBS for 15 $\mathrm{min}$ at room temperature. Fixed cells were washed three times with PBS and then permeabilized with $0.1 \%$ saponin (Sigma, S4521-10G) in PBS for $15 \mathrm{~min}$ at room temperature. After permeabilization, cells were treated with $1 \% \mathrm{BSA} / 0.1 \%$ saponin in PBS for $45 \mathrm{~min}$ and were incubated 
with primary antibody (mouse monoclonal antibody against RIBEYE(B) domain/CtBP2, 1:250 in blocking solution) overnight at $4^{\circ} \mathrm{C}$. After three washes with PBS, cells were incubated for $1 \mathrm{~h}$ at room temperature with chicken anti-mouse secondary antibody conjugated with AlexaFluor488 (1:1000 in blocking solution). After washing with PBS, coverslips were mounted on glass cover slides with antifade solution and sealed with nail polish.

\section{Analyses of synaptic ribbon-associated endocytic activity in} synaptic terminals of isolated mouse photoreceptors

Endocytic activity of isolated photoreceptors was visualized with sulforhodamine 101 (SR101) (Sigma, S7635), a fluid-phase endocytic marker or with the fixable SR101 analog Texas Red-hydrazide (Invitrogen, T6256). Isolated mouse photoreceptors, prepared as described above, were incubated for $2 \mathrm{~min}$ at room temperature with $1 \mu \mathrm{M}$ SR101/ Texas Red-hydrazide at a light density of $\approx 0.3 \mathrm{~cd} / \mathrm{m}^{2}$. SR101/Texas Redhydrazide was dissolved in resting solution (RS, containing $132 \mathrm{~mm}$ $\mathrm{NaCl}, 3 \mathrm{~mm} \mathrm{KCl}, 1 \mathrm{~mm} \mathrm{MgCl} 2 \times 6 \mathrm{H}_{2} \mathrm{O}, 2 \mathrm{~mm} \mathrm{CaCl}_{2}, 10 \mathrm{~mm}$ sodium pyruvate, $10 \mathrm{~mm}$ glucose, $10 \mathrm{~mm}$ HEPES, $\mathrm{pH} 7.4 ; \approx 300 \mathrm{mOsm} / \mathrm{L}$ ). After uptake, photoreceptors were rinsed three times with LCS. For two separate experiments, photoreceptors were either incubated with the dynamin inhibitor dynasore (100 $\mu \mathrm{M}$ in RS; $30 \mathrm{~min}$ ) to block dynamindependent, ribbon-associated endocytosis or with $1 \mathrm{mM} \mathrm{Co}^{2+}$ added to $\mathrm{RS}$ to block $\mathrm{Ca}^{2+}$ entry through voltage-gated calcium channels (10 min, $37^{\circ} \mathrm{C}$ ) before the incubation with SR101. After uptake, cells were rapidly washed 3 times with LCS and fixed with 4\% PFA for $15 \mathrm{~min}$ at room temperature. For immunolabeling, fixed cells were processed as described above. For quantification of SR101 uptake, integrated fluorescence intensity of SR101 signals per ribbon area were measured with Fiji/ImageJ. The RIBEYE immunosignals served as reference controls and were identical between Tulp1 knock-out and littermate control mice. Statistical analyses were performed with two-sided Student's $t$ tests. For the quantification of the SR101 uptake analyses, images were acquired from isolated photoreceptor terminals under exactly the same conditions with the A1R microscope using the reuse image settings (scan area 264 pixels $\times 264$ pixels; pixel size $1.24 \mu \mathrm{m}$; dwell time $2.3 \mu$ s, scan speed $1 \mathrm{scan} / 4 \mathrm{~s}$; pinhole size $27.8 \mu \mathrm{m}, \mathrm{HV}: 104$; offset: - 127, laser power $3.5 \%)$. Image acquisition was performed blindly without knowledge of genotype from which photoreceptors were isolated.

\section{Retinal slice preparation for FM1-43 labeling of} photoreceptor synapses

Retinas were isolated from postnatal day (P) 16 old wild-type and Tulp1 knock-out mice within 5 min postmortem (in dim ambient light, $\approx 30$ $\mathrm{cd} / \mathrm{m}^{2}$ ). Enucleated eyes were bisected at the equatorial plane, and posterior eye cup was transferred into ice-cold low calcium solution (LCS; containing $132 \mathrm{~mm} \mathrm{NaCl}, 3 \mathrm{~mm} \mathrm{KCl}, 1 \mathrm{~mm} \mathrm{MgCl}_{2} \times 6 \mathrm{H}_{2} \mathrm{O}, 0.5 \mathrm{~mm}$ $\mathrm{CaCl}_{2}, 10 \mathrm{~mm}$ sodium pyruvate, $10 \mathrm{~mm}$ glucose, $10 \mathrm{~mm}$ HEPES, pH 7.4; $\approx 300 \mathrm{mOsm} / \mathrm{L}$ ). LCS was saturated with $5 \% \mathrm{CO}_{2} / 95 \% \mathrm{O}_{2}$ before use. From the posterior eyecup, the retina was gently peeled off from the pigment epithelium. Four cuts were made in the retina so that it could be flat-mounted. Isolated and cut retina from P16 Tulp1 wild-type and knock-out mice were transferred onto black-gridded nitrocellulose filter membranes (Millipore, \#HABG01300) with ganglion cell side facing nitrocellulose membrane. The membrane filters with the retina on top and some LCS (to prevent drying of the retinas) were transferred to a silica sieve funnel to which a $20 \mathrm{ml}$ syringe was connected. Gentle suction was applied to the attached retina via the attached syringe to promote attachment of the retina to the filter.

\section{Slice preparation}

The retina attached on top of the nitrocellulose filter was transferred to a glass slide with $200-300 \mu$ l of LCS solution. The glass slide with the attached retina was transferred to the cutting stage of Werblin-type tissue slicer. Some streaks of Vaseline that previously added to the glass slide prevented lateral movements of the filter during subsequent sectioning. Retina slices of $\approx 500 \mu \mathrm{m}$ thickness were sectioned with the slicer. Slices were then immediately transferred onto a glass coverslip with parallel streaks of Vaseline on it. The gaps between the streaks of Vaseline were filled in advance with resting solution (RS, containing $132 \mathrm{~mm} \mathrm{NaCl}, 3$ mм KCl, $1 \mathrm{~mm} \mathrm{MgCl}_{2} \times 6 \mathrm{H}_{2} \mathrm{O}, 2 \mathrm{~mm} \mathrm{CaCl}_{2}, 10 \mathrm{~mm}$ sodium pyruvate, 10 mm glucose, $10 \mathrm{~mm}$ HEPES, pH 7.4; $\approx 300 \mathrm{mOsm} / \mathrm{L}$ ). RS was saturated with $5 \% \mathrm{CO}_{2} / 95 \% \mathrm{O}_{2}$ before use. Slices were carefully picked from the cutting platform with fine tweezers, turned by $90^{\circ}$, and fixed between the Vaseline streaks. By this way, all retinal layers were visible from the photoreceptors on the free outer side of the slice to the ganglion cells that were attached to the filter surface.

\section{Loading of retina slices with FM1-43 and immunolabeling}

Retina slices were incubated for $10 \mathrm{~min}$ in resting solution (RS) containing $5 \mu \mathrm{M}$ FM1-43 (fixable FM1-43: FM1-43FX; Invitrogen, \#F35355) at $37^{\circ} \mathrm{C}$ in complete darkness $\left(0.02 \mathrm{~cd} / \mathrm{m}^{2}\right)$, similar to a previously described procedure (Rea et al., 2004). After labeling, retina slices were rinsed 3 times with RS and fixed with ice-cold $4 \%$ PFA for $10 \mathrm{~min}$. After fixing, slices were gently rinsed three times with RS and permeabilized with permeabilization buffer (PBS, $\mathrm{pH} 7.4$, containing $0.5 \%$ Triton $\mathrm{X}-100$ and $0.5 \% \mathrm{BSA}$ ) for $20 \mathrm{~min}$. Slices were than incubated overnight at $4^{\circ} \mathrm{C}$ with CtBP2 antibody at dilution of 1:400 (in permeabilization buffer). Slices were washed three times with RS and incubated with 1:1000 dilution of Alexa CAM 568 for $1 \mathrm{~h}$ at room temperature and again washed three times with RS. Labeled slices of P16 Tulp1 wild-type and knockout mice were than analyzed with the confocal microscope (Nikon, A1R-MP). In control experiments, wild-type retinal slices were incubated either with dynasore (100 $\mu \mathrm{M}$ in RS; $30 \mathrm{~min}$ ) or LCS containing 4 mu cobalt ions $\left(\mathrm{Co}^{2+}\right)\left(10 \mathrm{~min}, 37^{\circ} \mathrm{C}\right)$ to make sure that FM1-43 uptake is dependent upon $\mathrm{Ca}^{2+}$-dependent vesicle cycling. After incubation with $\mathrm{Co}^{2+}$, slices were subsequently treated with $5 \mu \mathrm{M}$ FM1-43 in RS (10 $\min , 37^{\circ} \mathrm{C}$ ) and were further processed for labeling as described above.

\section{Blocking of $\mathrm{PIP}_{2}$ antibody: preabsorption experiments}

For preabsorption blocking experiments, PIP $_{2}$ (Avanti Polar Lipids; 840046) and L- $\alpha$-phosphatidylcholine (Avanti Polar Lipids, 840053P) were dissolved in chloroform at a concentration of $10 \mathrm{mg} / \mathrm{ml}$ (lipid/ chloroform). From each solution, $20 \mu \mathrm{g}(2 \mu \mathrm{l})$ was spotted on a nitrocellulose membrane (PeqLab). After evaporation of the chloroform, nitrocellulose membranes were treated with 3\% BSA and $0.1 \%$ Tween 20 in PBS ( $1 \mathrm{~h}$, room temperature). In the next step, the dots were cut out and cut into small pieces. The pieces from each dot were added to PIP antibody solutions (diluted 1:20) for overnight incubation on a turning wheel at $4^{\circ} \mathrm{C}$ and used on the next day for immunolabeling experiments (data not shown).

\section{Coimmunoprecipitation of retinal protein complexes}

First, three bovine retinas were homogenized in $5 \mathrm{ml}$ of lysis buffer (containing $150 \mathrm{~mm} \mathrm{NaCl}, 50 \mathrm{~mm}$ Tris- $\mathrm{HCl} \mathrm{pH}$ 8.0, 1\% Triton X-100, 0.1\% NP40, 10\% glycerol) supplemented with protease inhibitors (cOmplete ULTRA Tablets, Mini, EDTA-free, EASYpack, Roche Applied Science). After homogenization with an Ultraturrax $(3 \times 1 \mathrm{~min}$; on ice $)$, the lysate was transferred into a $5 \mathrm{ml}$ syringe and ejected through a 20 gauge needle. This procedure was repeated 10 times. The lysate was incubated on ice for $1 \mathrm{~h}$ with gentle shaking. Afterward, the lysate was centrifuged at $4500 \mathrm{rpm}$ (Eppendorf centrifuge; $45 \mathrm{~min}, 4^{\circ} \mathrm{C}$ ) and the supernatant again at 13,000 $\mathrm{rpm}$ for $15 \mathrm{~min}$ (Eppendorf centrifuge). The precleared lysate was divided into three equal aliquots to which $20 \mu \mathrm{l}$ of washed protein A Sepharose beads were added. All three samples were incubated for $1 \mathrm{~h}$ at $4^{\circ} \mathrm{C}$ on a turning wheel. After this preincubation, one sample was kept with protein A Sepharose beads only. To the other two vials, $\approx 75 \mu \mathrm{g}$ of either monoclonal antibody against Tulp1 (5G2-4) or anti-panSV2 (control; Buckley and Kelly, 1985) was added. The samples were incubated overnight at $4^{\circ} \mathrm{C}$ on a turning wheel. After overnight incubation, samples were centrifuged for $1 \mathrm{~min}$ at $2500 \mathrm{rpm}$ in an Eppendorf centrifuge to pellet the protein A-Sepharose beads. The supernatant was removed and the beads were washed 4 times with $1 \mathrm{ml}$ of lysis buffer by resuspending them and then let them settle by gravity for $\approx 8 \mathrm{~min}$. The last pellet was boiled with $25 \mu \mathrm{l}$ SDS loading buffer for $5 \mathrm{~min}$ and subjected to SDSPAGE followed by Western blotting with the indicated antibodies.

Purification of synaptic ribbon complexes from the bovine retina Synaptic ribbon complexes were purified from photoreceptor synapses of the bovine retina as previously described (Schmitz et al., 2000). 
A

a) WB: anti-Tulp1 (5G2-4)

b) WB: anti-EEA1

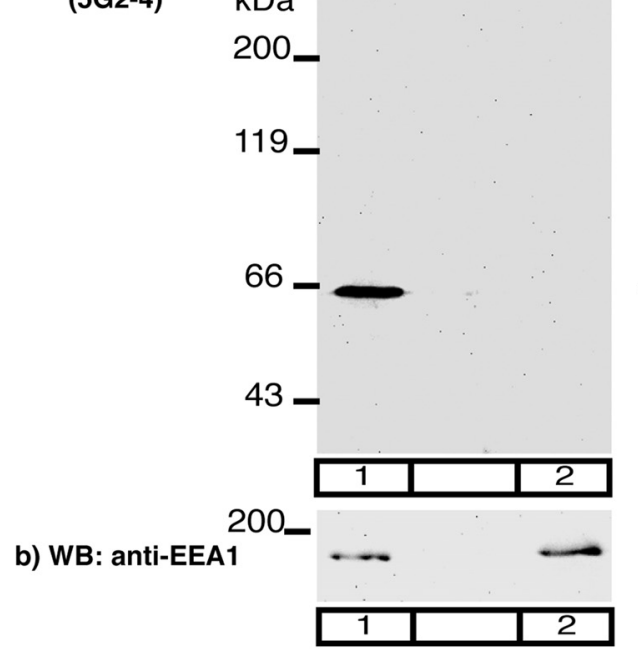

c) WB: anti-Tulp1 $\mathrm{kDa}$ (T1N1)

B

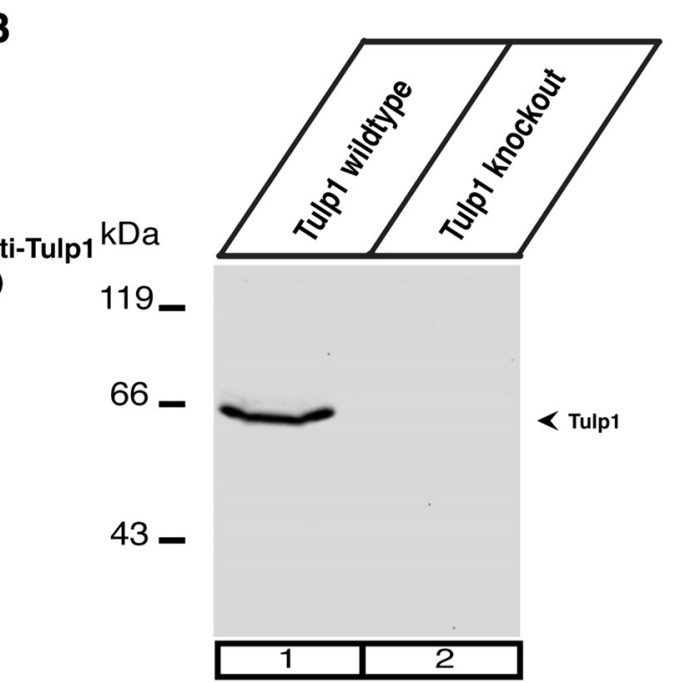

d) WB: anti-tubulin

e) WB: anti-RIBEYE

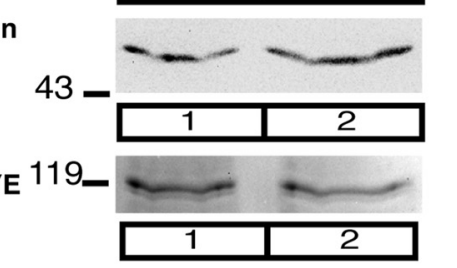

Figure 1. $\quad \boldsymbol{A}, \boldsymbol{B}$, Characterization of polyclonal and monoclonal Tulp1 antibodies in Western blot analyses of retinal lysates from Tulp1 knock-out mice and control mice. $A$, Monoclonal mouse antibody 5G2-4 on retinal lysates from wild-type ( $\boldsymbol{A} \boldsymbol{a}$, lane 1$)$ and Tulp1 knock-out tissue ( $\boldsymbol{A} \boldsymbol{a}$, lane 2). $\boldsymbol{B}$, Rabbit polyclonal antibody T1N1 on retinal lysates from wild-type (BC, lane 1) and Tulp1 knock-out tissue ( $B C$, lane 2). A single band at $\approx 60 \mathrm{kDa}$ is detected in retinal lysates from wild-type mice both by the monoclonal and the polyclonal antibody against Tulp1 $(\boldsymbol{A} \boldsymbol{a}$, lane $1 ; \boldsymbol{B C})$. This band is absent in the Tulp1 knock-out mice $(\boldsymbol{A} \boldsymbol{a}$, lane $2 ; \boldsymbol{B} \boldsymbol{C}) \cdot \boldsymbol{b}-\boldsymbol{e}$, Blots were stripped and reprobed with the indicated antibodies to verify equal loading of samples. Three experiments from three animals each.

YTH analyses. YTH analyses were performed exactly as previously described (Alpadi et al., 2008; Magupalli et al., 2008; Venkatesan et al., 2010; Dembla et al., 2014).

\section{Results}

Tulp1 is highly enriched in the $\mathrm{PIP}_{2}$-rich periactive zone surrounding the synaptic ribbon in photoreceptor synapses of the bovine retina

For immunolabeling, we used a rabbit polyclonal peptide antibody against Tulp1 (T1N1). In Western blot analyses, this antibody detected a single protein band at the expected running position of Tulp1 at $\approx 60 \mathrm{kDa}$ in retinal lysates of wild-type mice (Fig. $1 B$, lane 1). This band was completely absent in retinal lysates of Tulp1 knock-out mice demonstrating the specificity of the antibody for Tulp1 (Fig. 1B, lane 2). Using confocal microscopy and SR-SIM immunolabeling analyses, we found Tulp1 highly enriched at the photoreceptor synaptic ribbon complex of the bovine retina (Fig. $2 A-F)$. Confocal microscopy showed a strong enrichment of Tulp1 at photoreceptor synaptic ribbons in the bovine retina (Fig. $2 A$ ). Side views of the photoreceptor synaptic ribbon complex obtained by SR-SIM analyses of single synapses also revealed a high enrichment of Tulp1 at the synaptic ribbon (Fig. 2B). Top views of the synaptic ribbon complex in SR-SIM analyses demonstrated a localization of Tulp1 directly lateral to the synaptic ribbon (Fig. 2C). The ring-like immunolabeled structure surrounding the synaptic ribbon is typical for the periactive zone (Wahl et al., 2013). The periactive zone of photoreceptor synapses is highly enriched with endocytic proteins (e.g., clathrin-heavy chain, dynamin, and dynamin-associated proteins) and is a hotspot of endocytic activity (Wahl et al., 2013; Dembla et al., 2014). Indeed, we found Tulp1 colocalizing with endocytic proteins (e.g., dynamin and clathrin heavy chain) at the periactive zone (Fig. $2 D, E$ ). Furthermore, $\mathrm{PIP}_{2}$, a signaling phospholipid im- portant for endocytosis, was also highly enriched at that site and colocalized with Tulp1 in the periactive zone of photoreceptor synapses in the bovine retina as analyzed by super-resolution imaging of single synapses (Fig. 2F). Quantification of the immunolabeling analyses further corroborated the immunolabeling results shown in Figure 2. In 79.28\%, TULP1 signals in the OPL localized to the synaptic ribbon as judged by colocalization with RIBEYE, performed as described in Materials and Methods by epifluorescence microscopy (tMCC TULP1: $0.7928 \pm 0.0453(\mathrm{SEM}) ; 19$ slices, 568 synapses; $N=$ 3; tMCC RIBEYE: $0.8390 \pm 0.0353$ (SEM); 19 slices, 568 synapses; $N=3$ ). Because TULP1 is known to bind to $\mathrm{PIP}_{2}$, we further analyzed the amount of $\mathrm{PIP}_{2}$ at the RIBEYE-labeled ribbon and the amount of TULP1 associated with $\mathrm{PIP}_{2}$. In $80.04 \%$ of all signals analyzed, Tulp1 colocalized with PIP $_{2}$ (tMCC TULP: $0.8004 \pm$ 0.0325 (SEM); 17 slices, 447 synapses, $N=3$; tMCC PIP 2 : $0.6465 \pm$ 0.0364 (SEM); 17 slices, 447 synapses, $N=3$ ) and $74.01 \%$ of $\mathrm{PIP}_{2}$ were found at the RIBEYE-labeled ribbon $\left(\mathrm{tMCC} \mathrm{PIP}_{2}: 0.7401 \pm\right.$ 0.0432 (SEM); 13 slices; 366 synapses; $N=3$; tMCC RIBEYE: $0.9433 \pm 0.0195$ (SEM); 17 slices; 447 synapses; $n=3$ ). Furthermore, Tulp 1 colocalized with the endocytic proteins clathrin (tMCC TULP: $0.9054 \pm 0.0263$ (SEM); tMCC clathrin: $0.8747 \pm 0.0142$ (SEM); 14 slices; 568 synapses; $N=3$ ) and dynamin (tMCC TULP: $0.8615 \pm 0.0392$ (SEM); tMCC dynamin: $0.8366 \pm 0.0420$ (SEM); 17 slices; 622 synapses; $N=3$ ).

Tulp1 knock-out mice show a loss of endocytic proteins in the periactive zone of photoreceptor ribbon synapses, whereas active zone proteins are not affected

To further address the role of Tulp1 in photoreceptor synapses, we analyzed Tulp 1 knock-out mice. In Tulp1 knock-out mice, we found strong alterations in the localization of periactive zone 

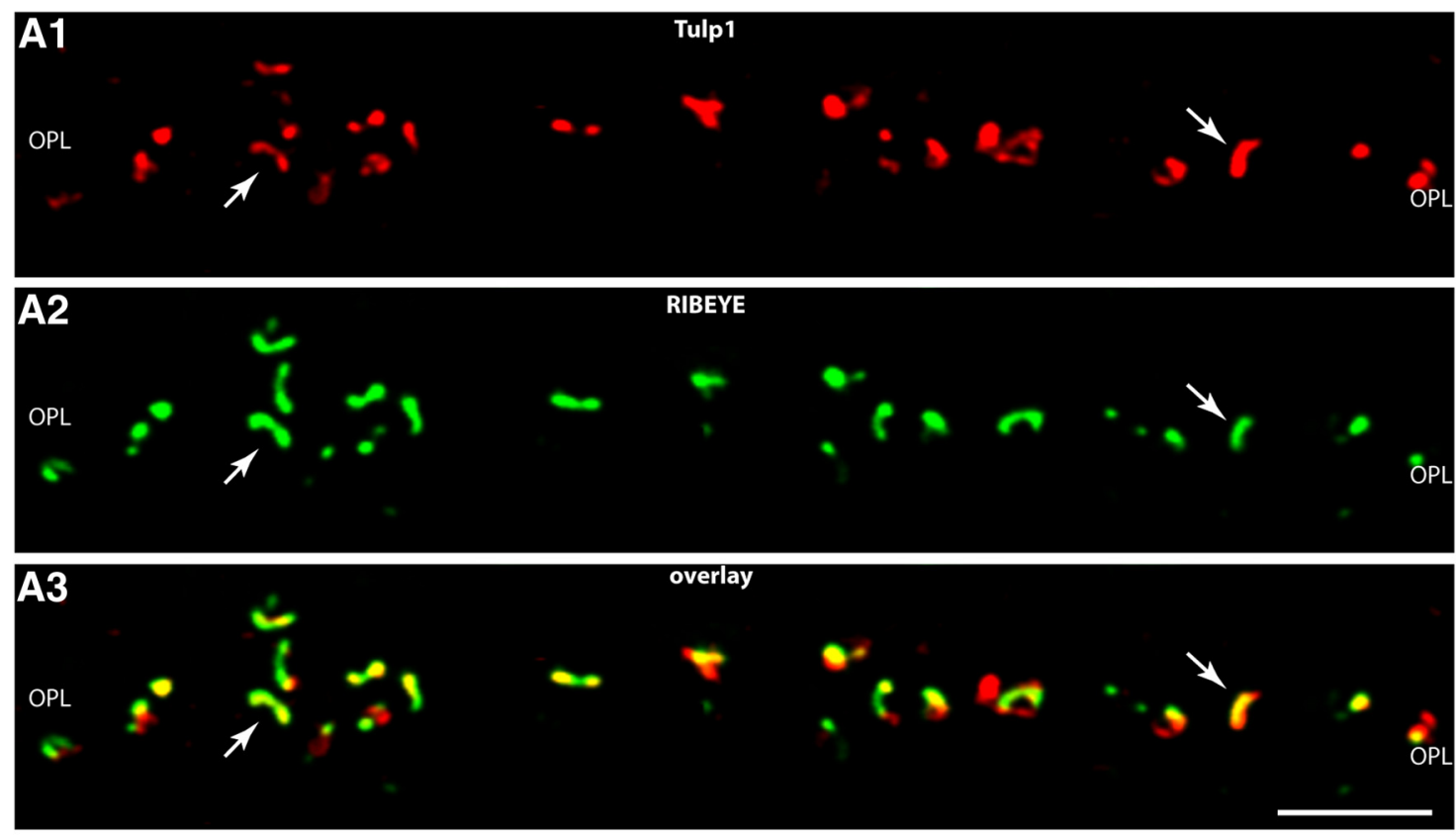
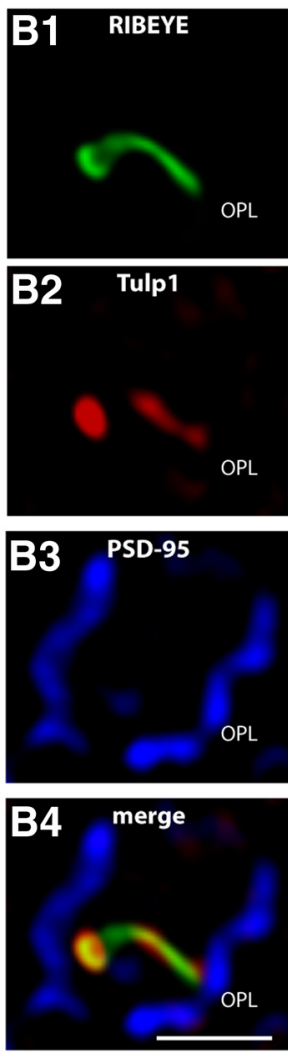

side view
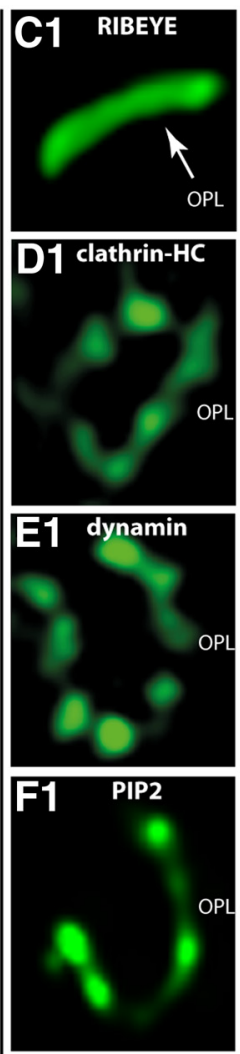

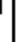
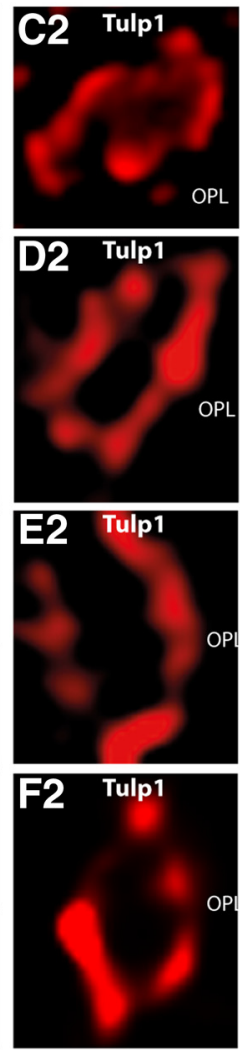

top views
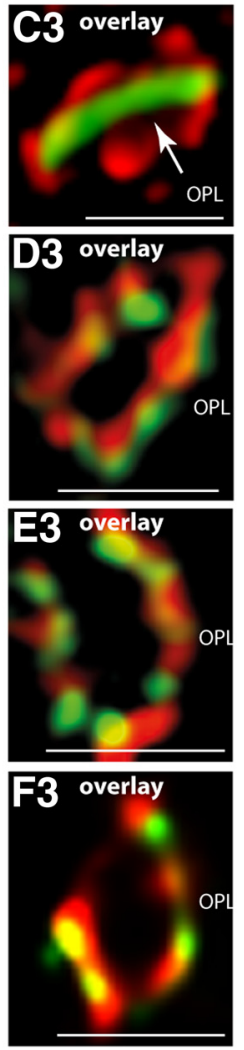

top view (SR-SIM)

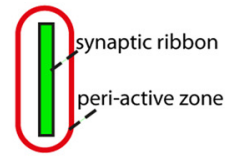

Figure 2. A, Low-magnification micrographs of $0.5-\mu \mathrm{m}$-thin resin sections from bovine retina immunolabeled with antibodies against Tulp1 and RIBEYE. In the OPL, where the photoreceptor ribbon synapses are located, there is a strong enrichment of Tulp1 at the synaptic ribbon complex (arrows). $\boldsymbol{A}$, Obtained by confocal imaging. $\boldsymbol{B}-\boldsymbol{F}$, Single synaptic ribbon complexes of rod photoreceptor synapses from bovine retina triple-immunolabeled $(\boldsymbol{B}) /$ double-immunolabeled $(\boldsymbol{C}-\boldsymbol{F})$ with the indicated antibodies. $\boldsymbol{B}-\boldsymbol{F}$, All images were obtained by SR-SIM. $\boldsymbol{B}$, Side view of a single synaptic ribbon complex (see also drawing in the right panel of the figure). The borders of a single presynaptic photoreceptor terminal were visualized by immunolabeling with anti-PSD-95 (B3). The single synaptic ribbon inside the presynaptic terminal was immunolabeled with Alexa-488 direct-labeled mouse monoclonal antibodies against RIBEYE(B) domain/CtBP2 (B1). Immunolabeling with rabbit polyclonal antibodies against Tulp1 (B2) demonstrated that Tulp1 is strongly enriched at the synaptic ribbon complex. $\mathbf{C}-\boldsymbol{F}$, Immunolabeled synaptic ribbon complexes are displayed as "top views" (looking from the ONL toward the synapses in the OPL, i.e., to the top of the synaptic ribbon; see also drawing in the right panel of the figure) to better resolve the periactive zone that is located lateral to the synaptic ribbon. C, Tulp1 (C2) is located directly lateral to the synaptic ribbon (C, arrows). At this site, Tulp1 colocalizes with clathrin heavy chain (D) and dynamin (E). Both dynamin and clathrin heavy chain are known to be highly enriched in the periactive zone of photoreceptor synapses (Wahl et al., 2013; Dembla et al., 2014). In the periactive zone, Tulp1 colocalizes also with $\mathrm{PIP}_{2}(\boldsymbol{F})$. In conclusion, both the antibody against Tulp1 as well as the antibodies against dynamin, clathrin heavy chain, and $\mathrm{PIP}_{2}$ surround the synaptic ribbon in a ring-like structure, which is typical for the periactive zone in photoreceptor synapses (Wahl et al., 2013; Dembla et al., 2014). $n=4$ independent experiments (four animals). $0 \mathrm{PL}, 0$ uter plexiform layer. Scale bars: $A, 5 \mu \mathrm{m} ; \boldsymbol{B}-\boldsymbol{F}, 1 \mu \mathrm{m}$. 
control
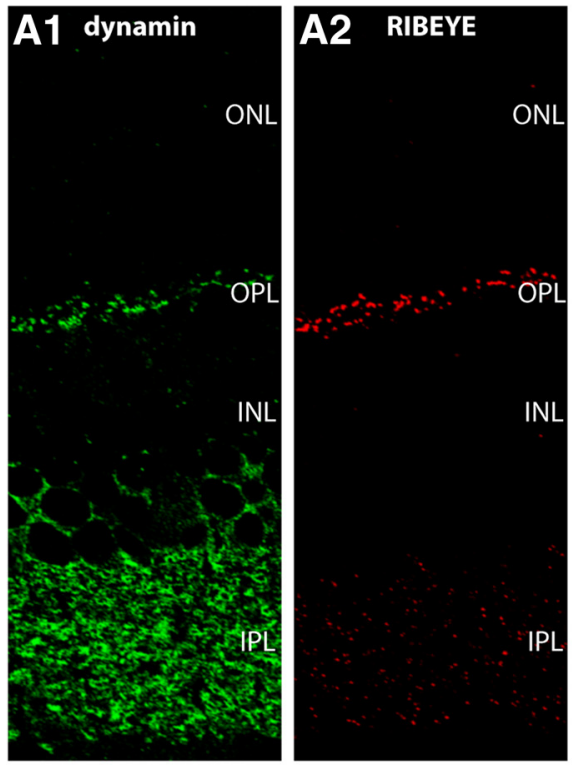

control

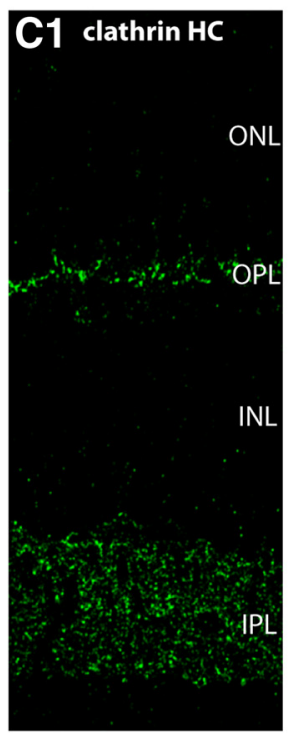

\section{C2 RIBEYE}

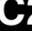
RIBEY
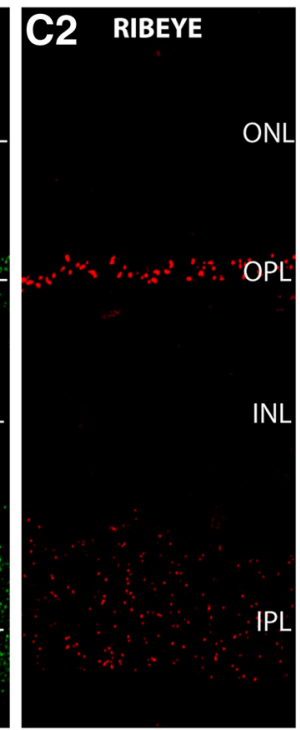
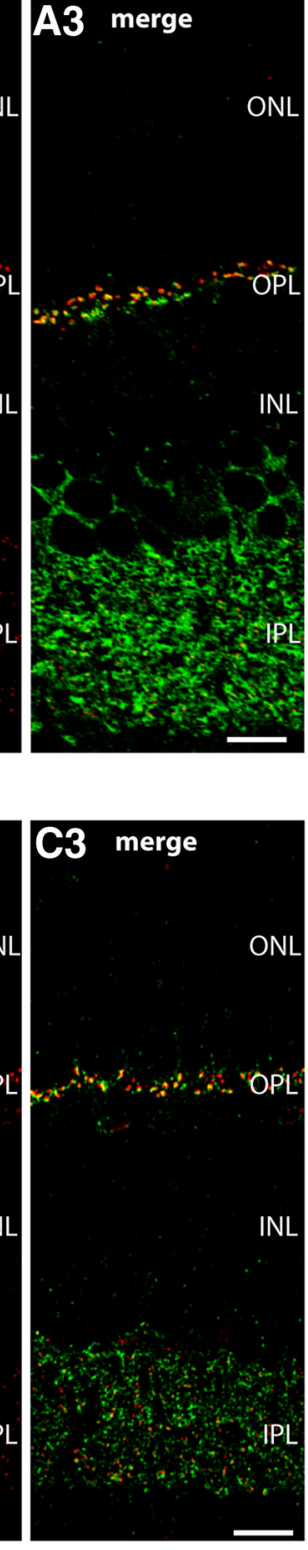

Tulp1 knockout

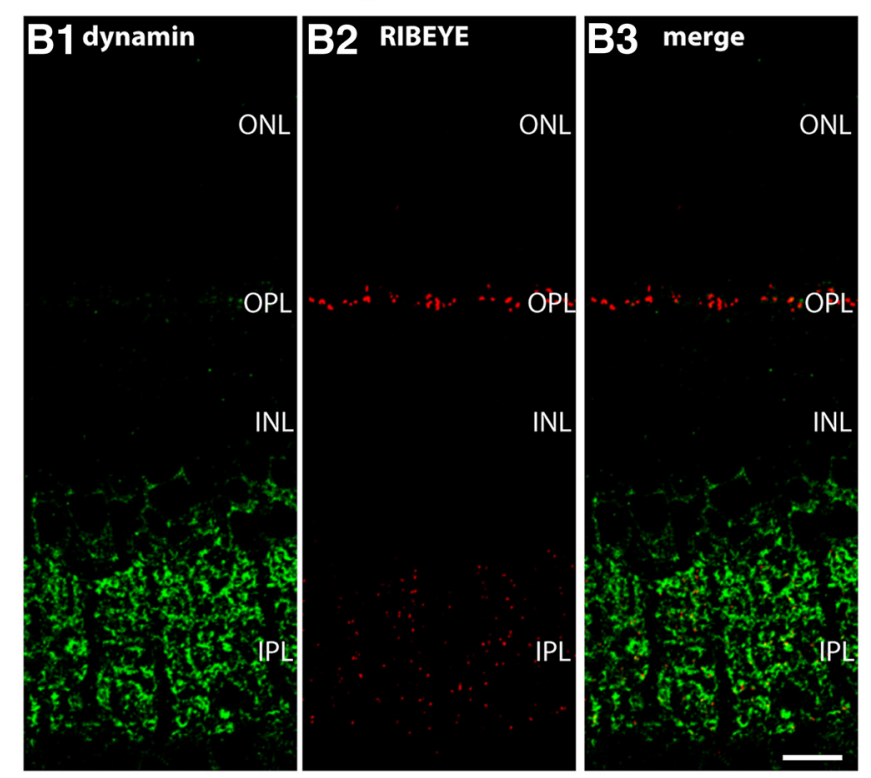

Tulp1 knockout
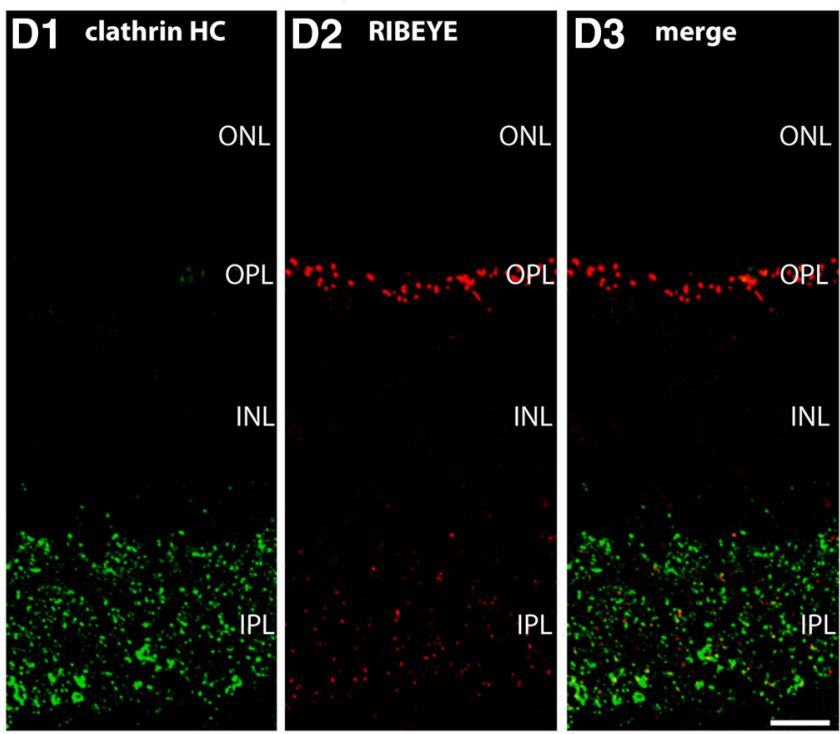

Figure 3. $\boldsymbol{A}-\boldsymbol{D}$, Low-magnification micrographs of 0.5 - $\mu \mathrm{m}$-thin resin sections from Tulp1 knock-out $(\boldsymbol{B}, \boldsymbol{D})$ retinas and littermate control $(\boldsymbol{A}, \boldsymbol{C})$ retinas that were immunolabeled with antibodies against dynamin and RIBEYE in $\boldsymbol{A}, \boldsymbol{B}$ and antibodies against clathrin heavy chain and RIBEYE in $\boldsymbol{C}, \boldsymbol{D}$. In wild-type mice, both dynamin and clathrin heavy chain were strongly expressed in the OPL and IPL, respectively. In the OPL, where photoreceptor synapses are located, dynamin and clathrin immunosignals were highly enriched at the synaptic ribbons of control mice, as previously described (Wahl et al., 2013). In contrast, in the OPL of Tulp1 knock-out mice, dynamin and clathrin were no longer enriched at the synaptic ribbon complex and were nearly completely absent from the OPL by immunofluorescence microscopy. In the IPL, dynamin and clathrin immunosignals remained unchanged in Tulp1 knock-out mice. Thus, the observed changes of dynamin and clathrin are restricted to photoreceptors in which Tulp1 is selectively expressed in the retina. For high-magnification analyses of single photoreceptor ribbon complexes, see Figure 4. ONL, Outer nuclear layer; INL, inner nuclear layer; OPL, outer plexiform layer; IPL, inner plexiform layer. Scale bars, $15 \mu \mathrm{m}$.

proteins already at postnatal day $(\mathrm{P}) 16$ using confocal microscopy and SR-SIM analyses (Figs. 3-5E). In wild-type mice, dynamin and clathrin heavy chain are highly enriched in the periactive zone of photoreceptor synapses (Wahl et al., 2013). In 16-d-old Tulp1 knock-out mice, dynamin and clathrin heavy chain were nearly completely absent from the periactive zone of photoreceptor synapses (Fig. $3 B, D$ ), whereas these proteins were highly enriched in the periactive zone of littermate control mice of the same age (Fig. $3 A, C$ ). This was observed both by confocal microscopy (Fig. 3) and SR-SIM analyses of single synapses (Fig. 4) as well as by quantitative analyses (Fig. $5 E, F$ ). In addition to endocytic proteins in the periactive zone, we also analyzed the localization of active zone proteins (i.e., voltage-gated calcium channels, Cav1.4; and RIM proteins) (Wang et al., 1997; Schmitz et al., 2000; tom Dieck et al., 2005) by confocal microscopy and SR-SIM analyses of single synapses (Figs. 5, 6). In contrast to the loss of endocytic proteins from the periactive zone of Tulp1 knock-out mice, active zone proteins (i.e., Cav1.4 and RIM1/2) remained unchanged and enriched at the active zone of 16-d-old Tulp1 knock-out mice (Figs. $5 B, D, 6 B, D$ ) similar to littermate control mice (Figs. $5 A, C, 6 A, C$ ). Quantification of the immunolabeling analyses (Fig. $5 G, H$ ) further corroborated the immunolabeling analyses shown in Figures $5 A-D, 6$. These findings indicated that Tulp1 is essential to specifically keep endocytic proteins enriched at the periactive zone. 

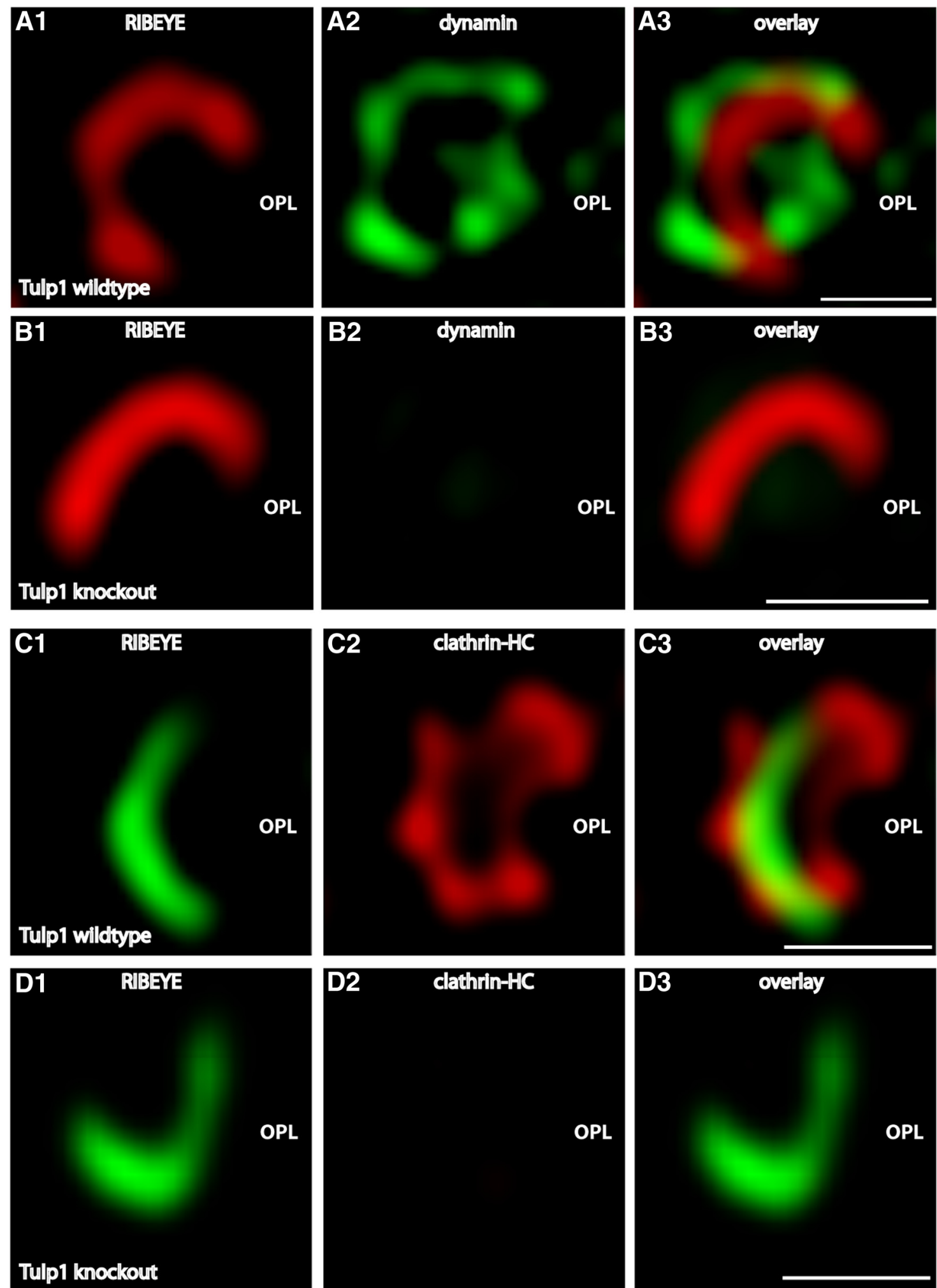

Figure 4. $\quad \boldsymbol{A}, \boldsymbol{B}$, Typical examples of single synaptic ribbon complexes (top views) of rod photoreceptor synapses double-immunolabeled with rabbit polyclonal antibodies against RIBEYE ( $\boldsymbol{A}, \boldsymbol{B})$ and mouse monoclonal antibodies against dynamin $(\boldsymbol{A}, \boldsymbol{B})$ in Tulp1 knock-out mice $(\boldsymbol{B})$ and littermate control mice $(\boldsymbol{A})$. $\boldsymbol{C}, \boldsymbol{D}$, Single synaptic ribbon complexes (top views) of rod photoreceptor synapses double-immunolabeled with rabbit polyclonal antibodies against RIBEYE $(\boldsymbol{C}, \boldsymbol{D})$ and mouse monoclonal antibodies against clathrin heavy chain $(\boldsymbol{C}, \boldsymbol{D})$ in Tulp1 knock-out mice $(\boldsymbol{D})$ and littermate control mice (C). Both dynamin and clathrin heavy chain are highly enriched in the periactive zone of control mice, as previously described (Wahl et al., 2013; Dembla et al., 2014). In contrast to littermate control mice, both dynamin and clathrin heavy chain were nearly completely absent from the periactive zone of Tulp1 knock-out mice $(\boldsymbol{B})$. The fluorescent dyes coupled to the secondary antibodies were switched on purpose in $C, D$ versus $A, B$ to demonstrate that the kind of fluorophore conjugated to the secondary antibody has no influence on the immunolabeling result. All images were obtained by SR-SIM. Representative results obtained from four animals (each genotype) of four litters (three experiments from each wild-type and knock-out animal). OPL, Outer plexiform layer. Scale bars, $1 \mu \mathrm{m}$. 

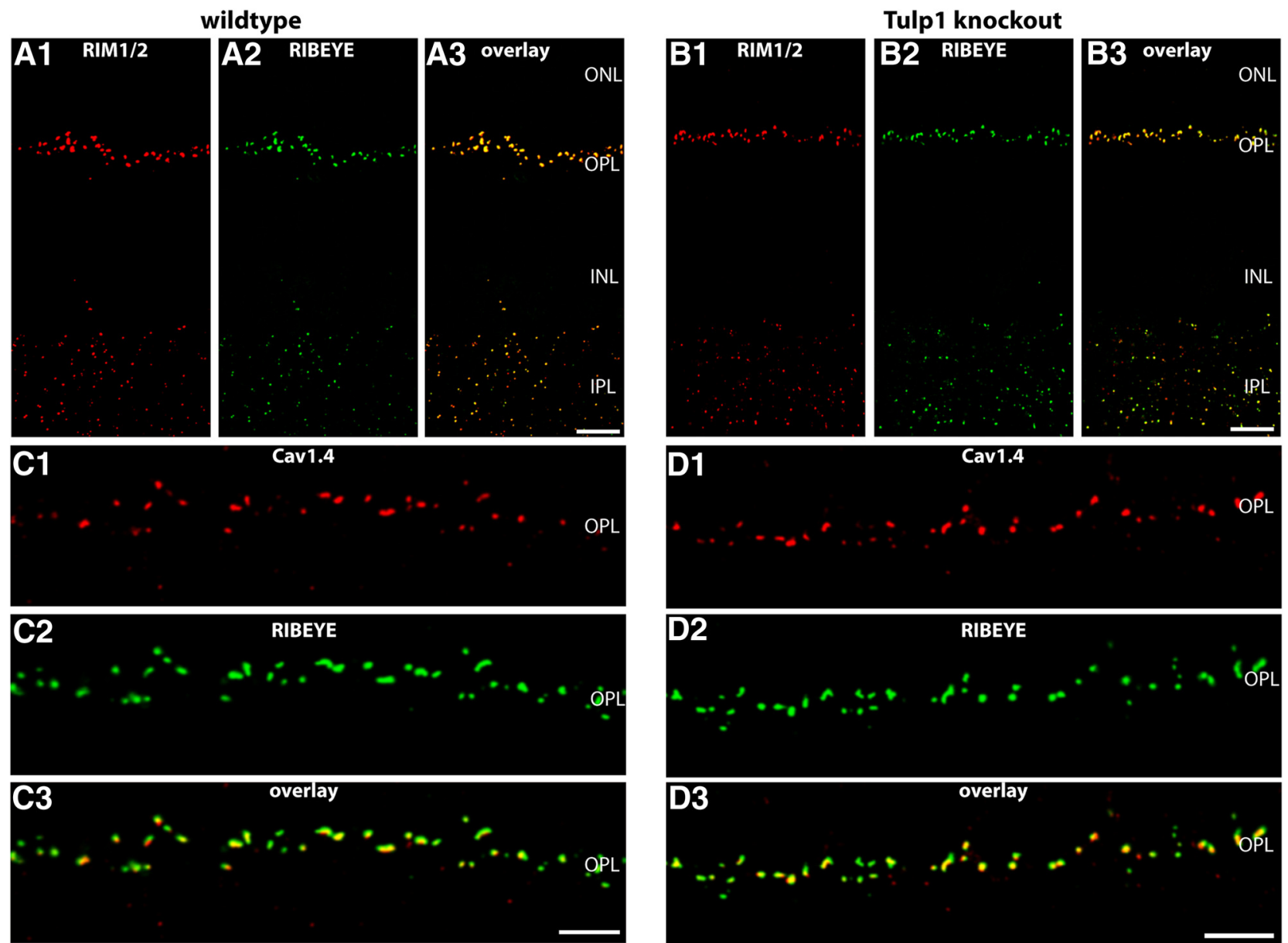

E

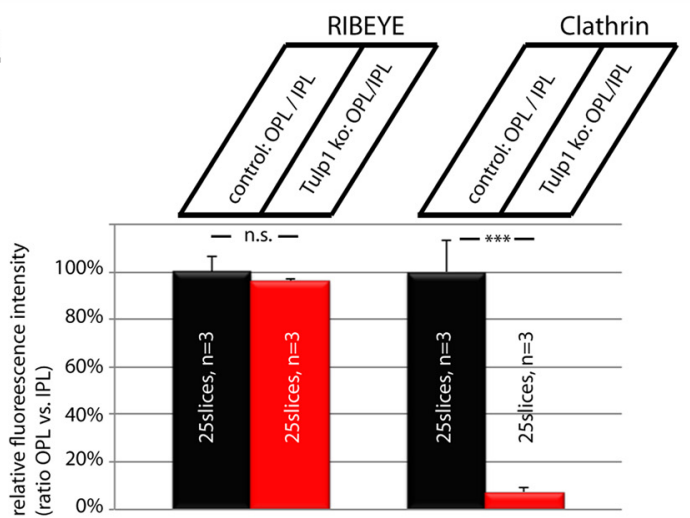

G

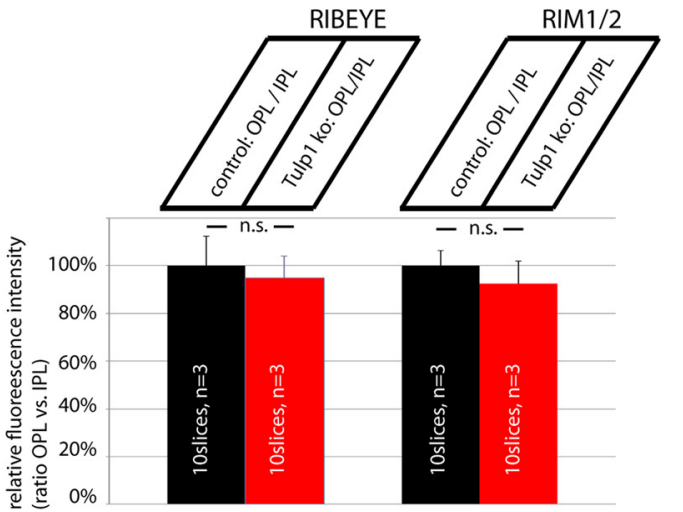

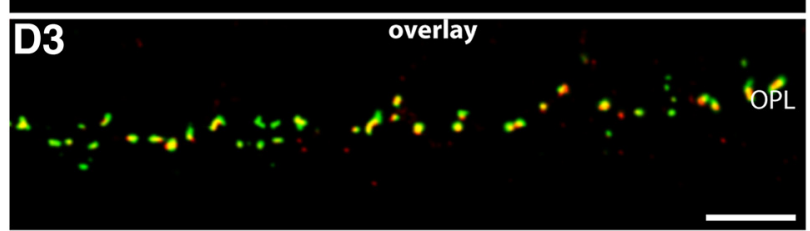

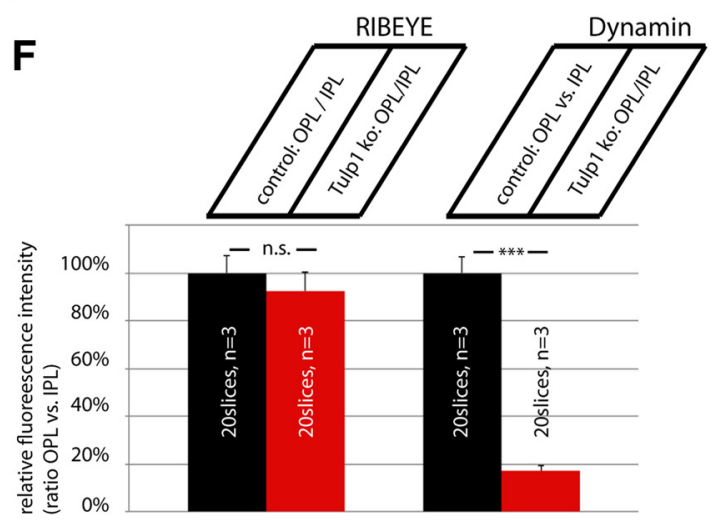

H
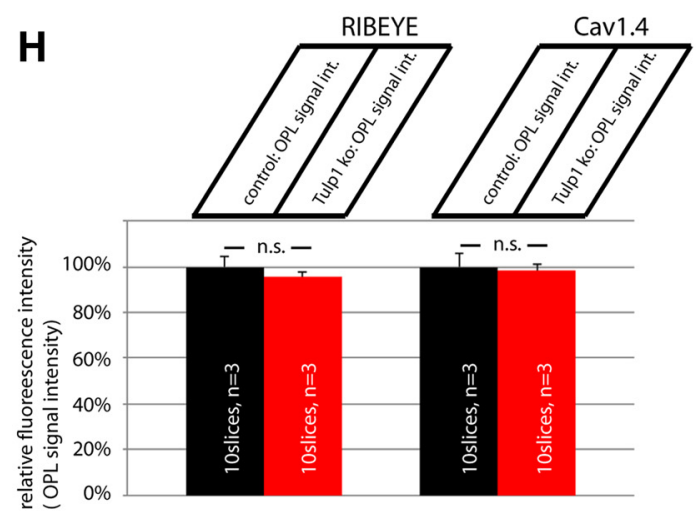

Figure 5. $A-D$, Low-magnification micrographs of $0.5-\mu \mathrm{m}$-thin resin sections from Tulp1 knock-out $(\boldsymbol{B}, \boldsymbol{D})$ retinas and control $(\boldsymbol{A}, \boldsymbol{C})$ retinas that were immunolabeled with rabbit polyclonal antibodies against RIM1/2 and mouse monoclonal antibodies against RIBEYE in $A, B$ and mouse monoclonal antibodies against Cav1.4 and rabbit polyclonal antibodies against RIBEYE in $C, D$. In both wild-type and Tulp1 knock-out mice, both RIM1/2 and Cav1.4 were strongly expressed in the OPL. In the OPL, where photoreceptor synapses are located, both (Figure legend continues.) 

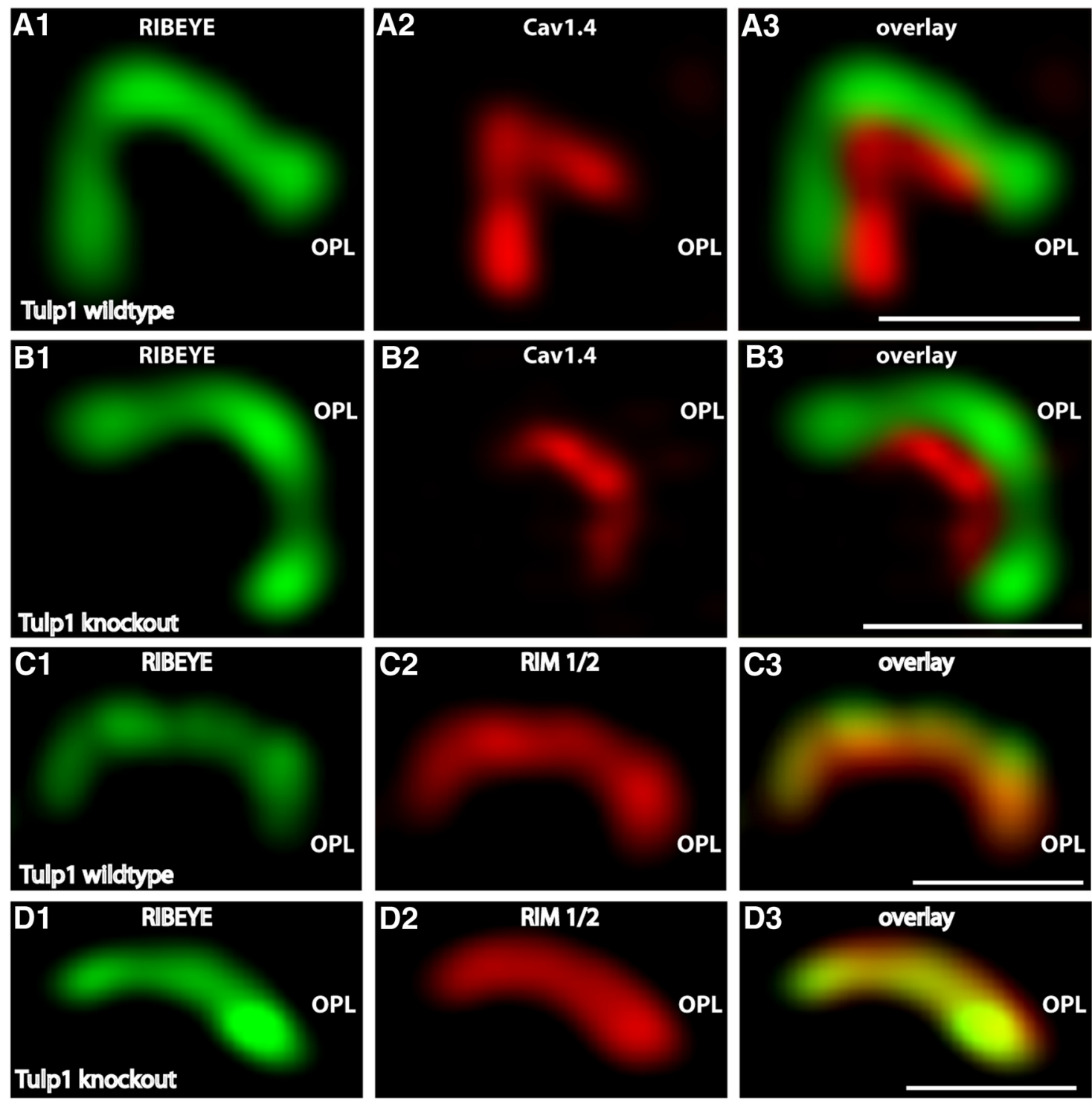

Figure 6. $\quad A, B$, Typical examples of single synaptic ribbon complexes (side views) of rod photoreceptor synapses double-immunolabeled with mouse antibodies against RIBEYE $(\boldsymbol{B}) /(\mathrm{CtBP2}(\boldsymbol{A}, \boldsymbol{B})$ and rabbit polyclonal antibodies against the pore-forming $\alpha 1$-subunit of Cav1.4 $(\boldsymbol{A}, \boldsymbol{B})$ in Tulp1 knock-out mice $(\boldsymbol{B})$ and littermate control mice $(\boldsymbol{A})$. Representative results obtained from four animals (each genotype) of four litters (three experiments from each wild-type and knock-out animal). $C, D$, Single synaptic ribbon complexes (side views) of rod photoreceptor synapses double-immunolabeled with mouse monoclonal antibodies against RIBEYE $(\boldsymbol{C}, \boldsymbol{D})$ and rabbit polyclonal antibodies against RIM1/2 (C, D) in Tulp1 knock-out mice $(\boldsymbol{D})$ and littermate control mice $(\boldsymbol{C})$. Three independent experiments from three animals of each genotype (littermate controls). In contrast to the endocytic proteins in the periactive zone, the localization of the active zone proteins Cav1.4 $(\boldsymbol{A}, \boldsymbol{B})$ and $\operatorname{RIM} 1 / 2(\boldsymbol{C}, \boldsymbol{D})$ remained unchanged in the Tulp1 knock-out mice. All images were obtained by SR-SIM. OPL, Outer plexiform layer. Scale bars, $1 \mu \mathrm{m}$.

\footnotetext{
(Figure legend continued.) RIM1/2 and Cav1.4 immunosignals were highly enriched at the synaptic ribbons, as previously described (Wahl et al., 2013). In contrast to the endocytic proteins of the periactive zone, the active zone proteins RIM1/2 and Cav1.4 remained unchanged in the OPL of Tulp1 knock-out mice. For high-magnification analyses of single photoreceptor ribbon complexes, see Figure 6. ONL, Outer nuclear layer; INL, inner nuclear layer; OPL, outer plexiform layer; IPL, inner plexiform layer. Scale bars: $\boldsymbol{A}, \boldsymbol{B}, 15 \mu \mathrm{m} ; \boldsymbol{C}, \boldsymbol{D}, 5 \mu \mathrm{m}$. $\boldsymbol{E}-\boldsymbol{H}$, The expression of dynamin, clathrin heavy chain, and RIM1/2 at photoreceptor ribbon synapses in the OPL was quantified and related to the IPL to correct for possible differences in section thickness $(\boldsymbol{E}-\boldsymbol{G})$. Only in $\boldsymbol{H}$ (quantification of Cav1.4), absolute fluorescence numbers were given for the OPL (with the control animals set to 100\%) because Cav1.4 is not expressed in significant amounts in the IPL (Grabner et al., 2015) (see also Materials and Methods). Quantification confirmed the loss of endocytic periactive zone proteins at photoreceptor synapses of Tulp1 knock-out mice, whereas the distribution of active zone proteins remains unaltered in Tulp1 knock-out mice. n.s., Nonsignificant. Error bars indicate SEM. ${ }^{* * *} p<0.001$.
}

Periactive zone endocytosis is severely disturbed in Tulp1 knock-out mice

The enrichment of Tulp1 in the periactive zone of photoreceptor synapses and the loss of endocytic proteins in the periactive zone of Tulp1 knock-out mice at P16 pointed to a possible involvement of Tulp1 in endocytosis at the periactive zone. Therefore, we measured endocytic uptake in photoreceptor synapses in 16d-old mice (i.e., in the time shortly after eye opening). For that purpose, we used retinal slices from littermate mouse retinas and FM1-43 as an uptake marker to measure endocytic activity. In agreement with previous studies (Wahl et al., 2013; Dembla et al., 2014), we found a strong uptake of FM1-43 at the synaptic ribbon complex in the periactive zone of control mice (Fig. $7 A, B$ ). The dependence of FM1-43 uptake on dynamin was shown by blocking experiments with dynasore that blocks dynamin activity (Fig. $7 C$ ), indicating the observed FM1-43 signal at the ribbon (Fig. 

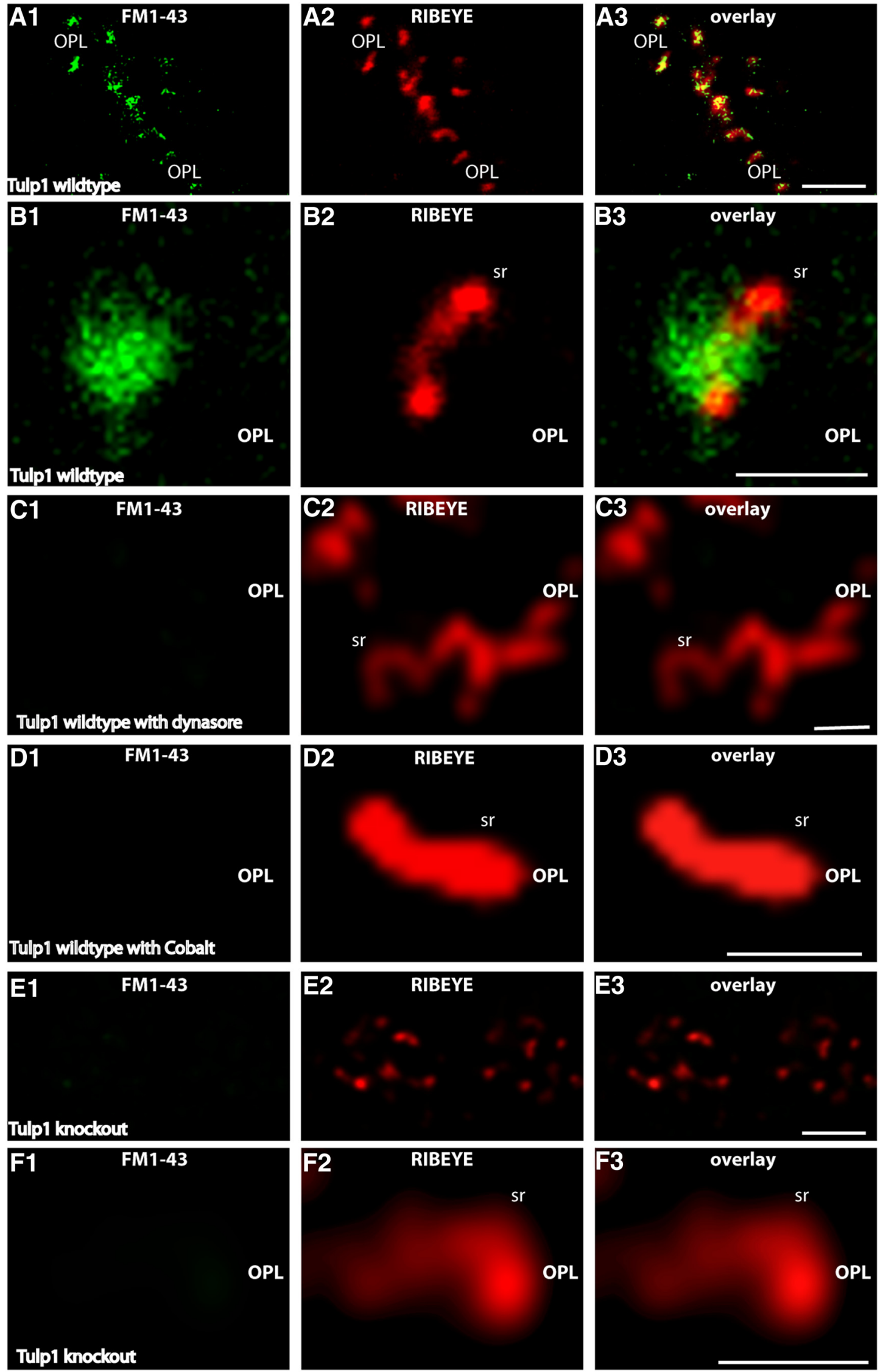

Figure 7. Retinal slices from P16-d-old control and Tulp1 knock-out mice (from the same litter) were incubated with FM1-43 as endocytic tracer. $\boldsymbol{A}, \boldsymbol{E}$, Low-magnification survey images of the OPL that contains the photoreceptor synapses in control animals $(\boldsymbol{A})$ and knock-out animals $(\boldsymbol{E}) \cdot \boldsymbol{B}-\boldsymbol{D}, \boldsymbol{F}$, Higher magnifications of single synaptic ribbon complexes. In the control mice, there was an intense uptake of FM1-43, particularly in close vicinity to the synaptic ribbon $(\boldsymbol{A}, \boldsymbol{B})$, similar to that previously described (Wahl et al., 2013). The uptake of (Figure legend continues.) 

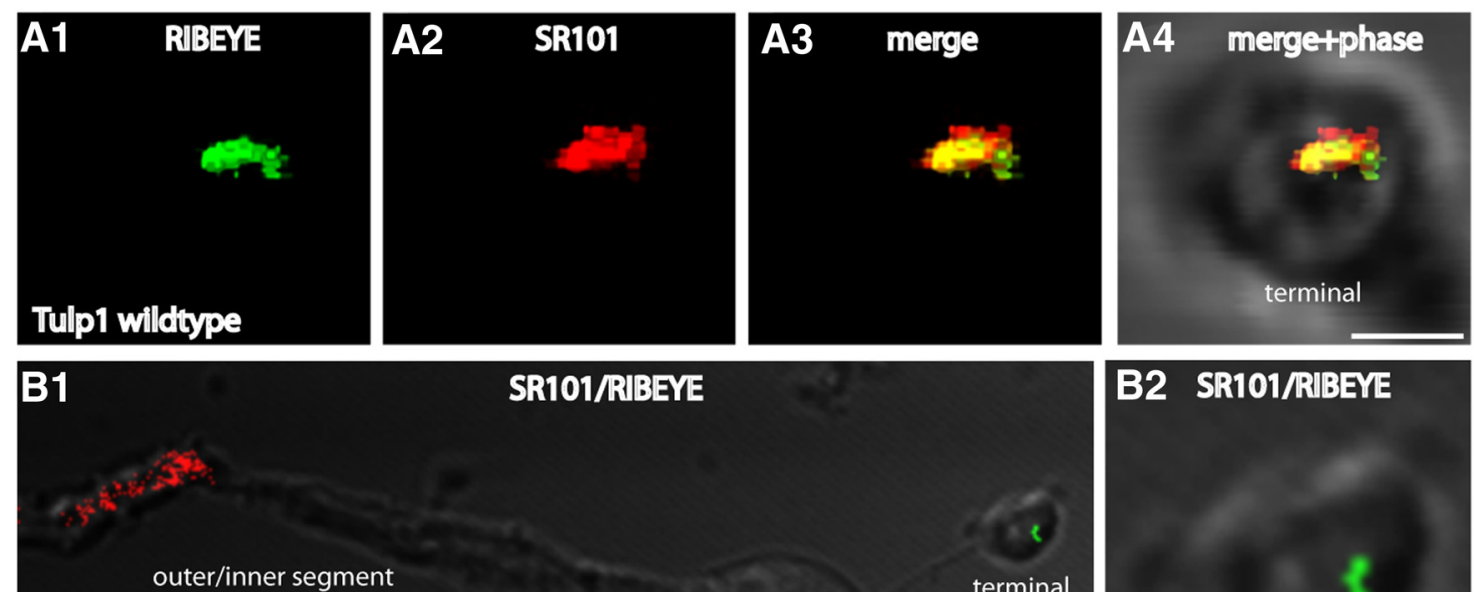

SR101/RIBEYE

Tulp1 wildtype (with dynasore)
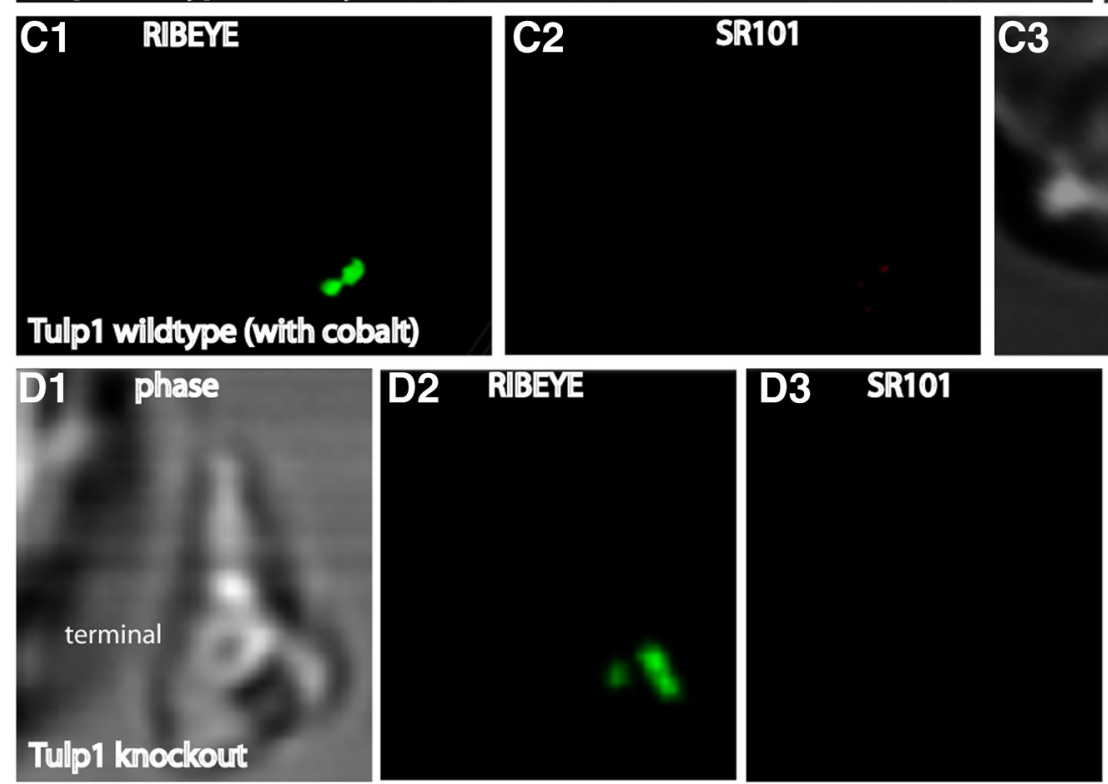

Figure 8. Photoreceptors were isolated from P16-d-old control and Tulp1 knock-out mice (from the same litter) and incubated with SR101 as extracellular uptake marker. $\boldsymbol{A}$, As previously described (Wahl et al., 2013), there was an intense uptake of SR101 (A2) in the synaptic terminals of wild-type mice in close vicinity to the synaptic ribbon (A1). The synaptic ribbon was labeled with anti-RIBEYE antibodies (A1). $\boldsymbol{A}$, Volume view of an immunolabeled terminal obtained from confocal stacks. This uptake of SR101 was dependent upon dynamin because inhibiting dynamin activity with dynasore resulted in a complete inhibition of SR101 uptake in the presynaptic terminal (B). Also, inhibitors of vesicle cycling (e.g., incubation with $\mathrm{C}^{2+}$ ), which blocks $\mathrm{Ca}^{2+}$ entry through voltage-gated $\mathrm{Ca}^{2+}$ channels, completely inhibited uptake of SR101 in synaptic terminals of wild-type mice (C). Uptake of SR101 was nearly completely abolished in photoreceptor terminals of untreated Tulp1 knock-out mice (D). $\boldsymbol{A}-\boldsymbol{D}$, Photoreceptor presynaptic terminals can be readily identified by the immunolabeled synaptic ribbon. Isolated photoreceptors were obtained from seven independent experiments (seven mice of each genotype, always littermates). In total, 122 photoreceptors were analyzed from knock-out animals and 109 from control littermates. Images were obtained by confocal imaging and acquired under identical conditions for animals of both genotypes (see also Materials and Methods). Scale bars, $\boldsymbol{A}-\boldsymbol{D}, 1 \mu \mathrm{m}$.

$\longleftarrow$

(Figure legend continued.) FM1-43 at the ribbon complex in control mice is dependent on the activity of dynamin. Blocking dynamin activity with dynasore completely abolishes uptake of FM1-43 at the synaptic ribbon in control mice $(\boldsymbol{C})$, indicating that the FM1-43 signal at the ribbon reflects endocytic uptake. The FM1-43 uptake is also dependent upon vesicle cycling as shown by incubation with cobalt ions $\left(\mathrm{Co}^{2+}\right)$, which block $\mathrm{Ca}^{2+}$ entry through Cav channels (D). In contrast to the littermate control mice, no uptake of FM1-43 was observed in Tulp1 knock-out mice next to the synaptic ribbon $(\boldsymbol{E}, \boldsymbol{F})$. Images were obtained by confocal imaging. Results were obtained from 20 slices from Tulp1 knock-out mice and littermate control mice (three mice for each genotype) and collected under identical conditions for both genotypes. sr, Synaptic ribbon; $0 \mathrm{PL}$, outer plexiform layer. Scale bars: $\boldsymbol{A}, \boldsymbol{E}, 5 \mu \mathrm{m} ; \boldsymbol{B}-\boldsymbol{D}, \boldsymbol{F}, 1 \mu \mathrm{m}$.
7 A,B) (Wahl et al., 2013; Dembla et al., 2014) is caused by dynamin-dependent endocytic uptake of FM1-43. The $\mathrm{Ca}^{2+}$ dependence of these processes was shown by blocking experiments with cobalt ions $\left(\mathrm{Co}^{2+}\right)$ (Fig. $\left.7 D\right)$. This uptake was completely absent in Tulp1 knock-out mice (Fig. 7E,F), demonstrating a defect in endocytic uptake of FM1-43 in Tulp1 knock-out mice.

Similarly, also in dissociated mouse photoreceptor cells isolated from 16-d-old littermate mice, we observed an intense endocytic uptake of the fluid phase marker SR101 in close vicinity to the synaptic ribbon (Fig. 8A), whereas the SR101 uptake was nearly completely abolished in Tulp1 knock-out mice (Fig. 8D). Quantification revealed that endocytic uptake of SR101 was re- 

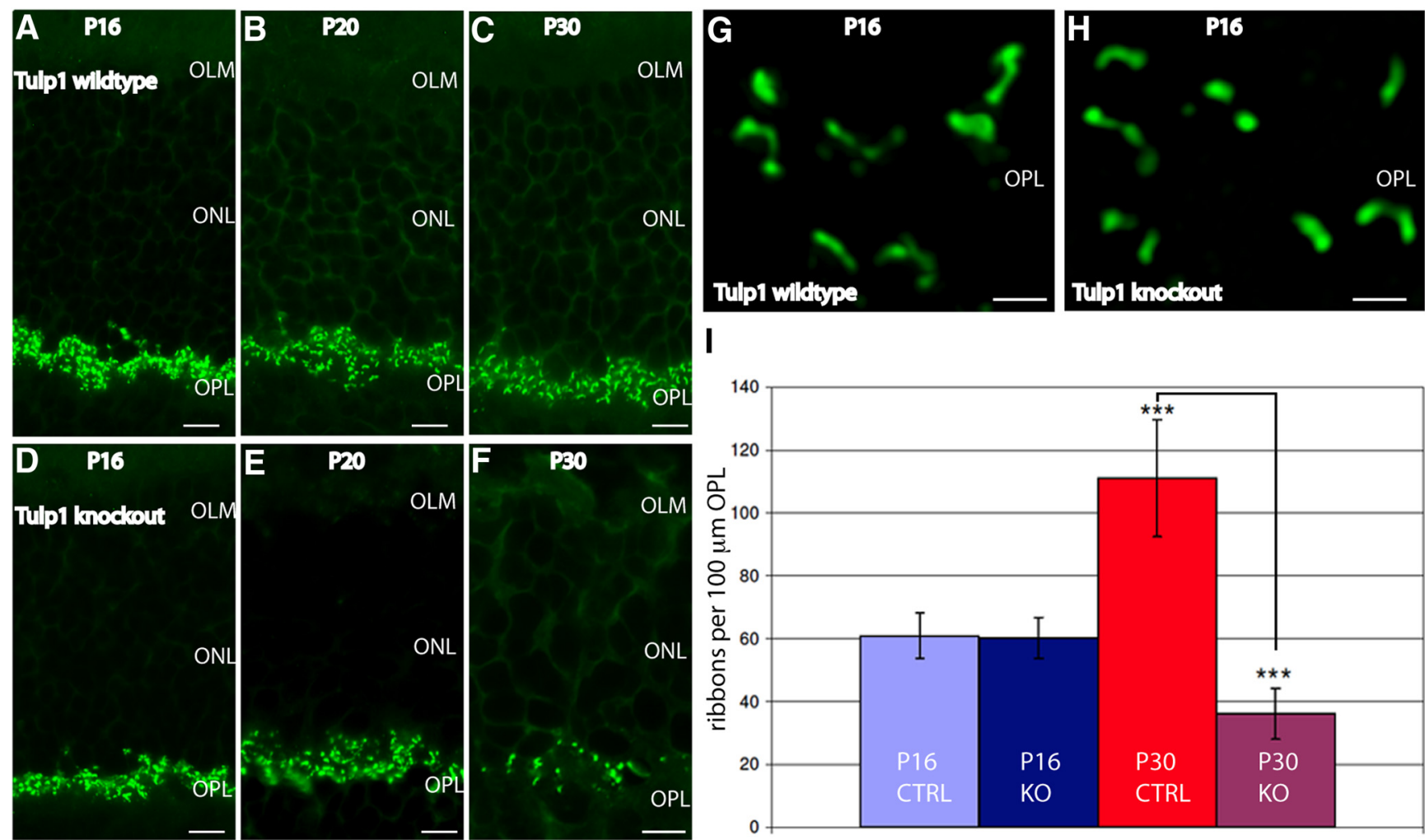

I
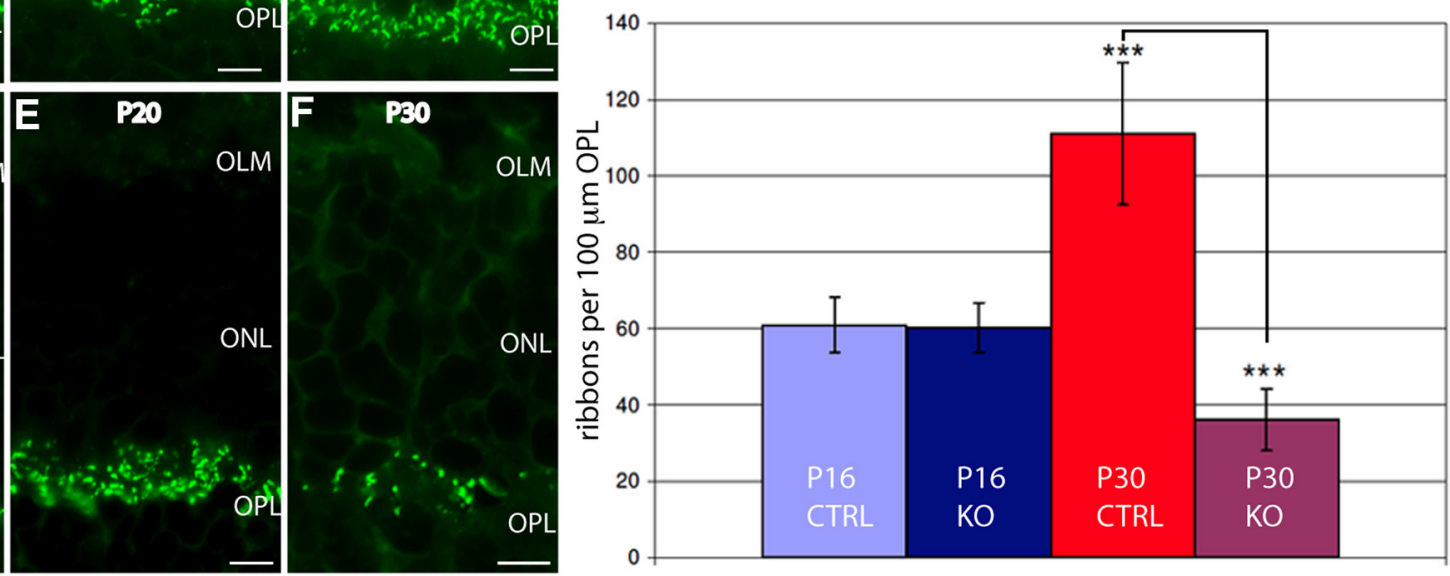

Figure 9. Immunolabeling of 0.5 - $\mu \mathrm{m}$-thin retinal sections from wild-type mice $(\boldsymbol{A}-\boldsymbol{C})$ and Tulp1 knock-out mice ( $\boldsymbol{D}-\boldsymbol{F})$ of the indicated ages immunolabeled with antibodies against RIBEYE. Images are conventional epifluorescence images. Four experiments from four animals of each genotype (littermates). Abbreviations: $0 \mathrm{LM}, 0$ uter limiting membrane; ONL, outer nuclear layer. Scale bars, $\boldsymbol{A}-\boldsymbol{F}, 5 \mu \mathrm{m} . \boldsymbol{G}, \boldsymbol{H}$, SR-SIM images of photoreceptor ribbons from P16-d-old wild-type $(\boldsymbol{G})$ and Tulp1 knock-out mice $(\boldsymbol{H})$. OLM, Outer limiting membrane; 0NL, outer nuclear layer; OPL, outer plexiform layer. Scale bars, $\mathbf{G}, \boldsymbol{H}, 1 \mu \mathrm{m}$. I, Quantification of photoreceptor synaptic ribbon numbers. ${ }^{* * *} p<0.001$. Error bars indicate SD.

duced to $10.2 \%$ of control values (mean[control] $=31.72$ arbitrary fluorescence units (A.U.); SEM = 1.21 A.U.; $n=109$ littermate control photoreceptors; seven independent experiments; mean[knock-out] $=3.24$ A.U.; SEM $=0.554$ A.U.; $n=$ 122 Tulp1 knock-out photoreceptors; seven independent experiments; $p<0.0001)$. Again, the $\mathrm{Ca}^{2+}$ dependence of tracer uptake was shown by blocking experiments using $\mathrm{Co}^{2+}$ (Fig. $8 \mathrm{C}$ ). The uptake of SR101 in these experiments was also dependent upon dynamin activity as shown by blocking analyses with dynasore (Fig. $8 B$ ). These findings further demonstrate that endocytosis in the periactive zone is severely disturbed in 16-d-old Tulp1 knock-out mice.

Tulp1 knock-out mice have a postnatal synaptic ribbon phenotype, and Tulp1 is found in a common complex with RIBEYE in situ

All functional analyses described above were done with 16-d-old mice. At this age shortly after eye opening, we observed no signs of neurodegeneration in Tulp1 knock-out mice. In Tulp1 knockout mice, the number of synaptic ribbons in photoreceptor synapses of the OPL were normal at postnatal day (P)16 as judged by immunolabeling analyses with antibodies against RIBEYE (Fig. $9 A-F)$. Quantification of synaptic ribbon numbers per length of OPL revealed identical values at P16 between littermate control mice and Tulp1 knock-out mice (Fig. 9I; [P16] control mice: mean: 60.9 ribbons per $100 \mu \mathrm{m}$ OPL length; SD 7.3, $n=10$; [P16] Tulp1 knock-out mice: 60.4 ribbons per $100 \mu \mathrm{m}$ OPL length, SD $6.5 ; n=10$ analyses from four animals of each genotype). Also, the shape of the synaptic ribbons in photoreceptor synapses of 16-d-old knock-out mice was normal compared with littermate control mice as judged by SR-SIM (Fig. 9G,H). But at postnatal day 30 (P30), significant differences in the number of synaptic ribbons were observed between Tulp1 knock-out mice and littermate control mice (Fig. 9A-F). Although the control mice showed the typical maturation-indicating, postnatal increase in the number of synaptic ribbons (Regus-Leidig et al., 2009; Ribic et al., 2014), synaptic ribbon numbers in Tulp1 knock-out mice were strongly reduced at P30 compared with the littermate control mice (Fig. 9I; ([P30] control mice: mean: 109.9 ribbons per $100 \mu \mathrm{m}$ OPL length; SD 35.4, $n=10$; [P30] Tulp1 knock-out mice: 36.1 ribbons per $100 \mu \mathrm{m}$ OPL length, SD 8.1; $n=10$ analyses from four animals of each genotype). These findings indicated that there could be an interdependence between Tulp1 and the synaptic ribbons.

This possibility was further confirmed by coimmunoprecipitation analyses using a newly generated monoclonal antibody against Tulp1 (5G2-4; Fig. 1A). The monoclonal Tulp1 antibody 5G2-4 not only efficiently immunoprecipitated Tulp1 from the bovine retina (Fig. $10 A b$, lane 1) but also coimmunoprecipitated RIBEYE (Fig. 10Aa, lane 1), demonstrating that RIBEYE and Tulp1 are part of a common retinal protein complex. In contrast to RIBEYE, tubulin was not enriched in the Tulp1 immunoprecipitated complex (Fig. 10Ac, lane 1). In addition, Tulp 1 was found to be present in isolated synaptic ribbon complexes (Fig. 10B) purified from the bovine retina as previously described (Schmitz et al., 2000). These findings are in line with the immunolocalization experiments that demonstrated a close colocalization of Tulp1 and RIBEYE at the synaptic ribbon complex. 
A

a) Western blot: anti-RIBEYE(B) (rabbit polyclonal)

\section{(rabit polyclonal)}

b) Western blot: anti-Tulp1 (rabbit polyclonal)

c) Western blot: anti-tubulin (mouse monoclonal)

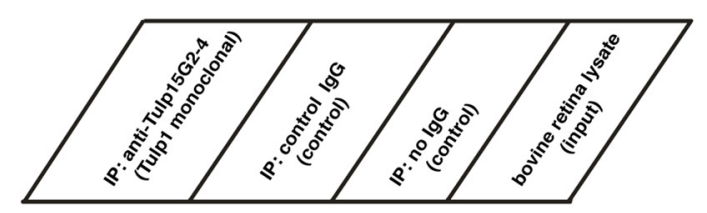

$\mathrm{kDa}$

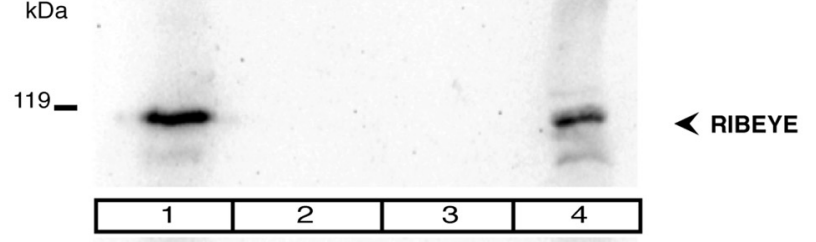

66

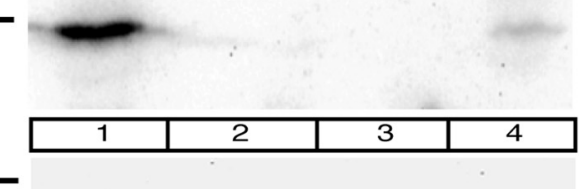

$66-$

$<$ Tubulin

B

$<$ Tulp1

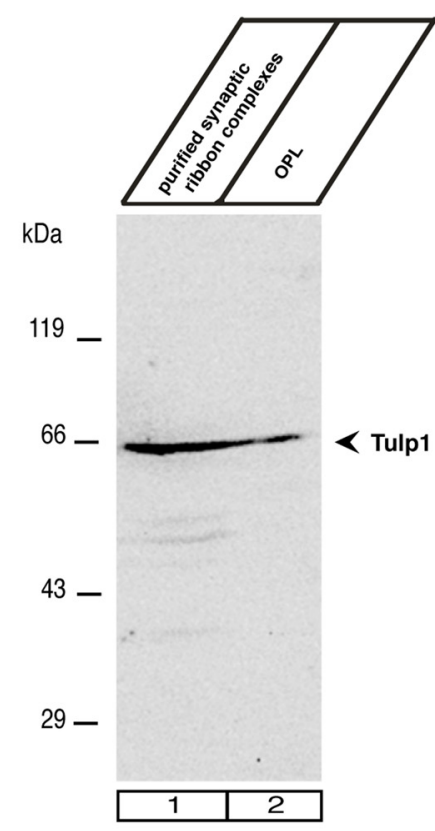

C Tulp1 interacts with the A-domain and the B-domain of RIBEYE

E Tulp1 disease mutants disrupt binding to RIBEYE(B)
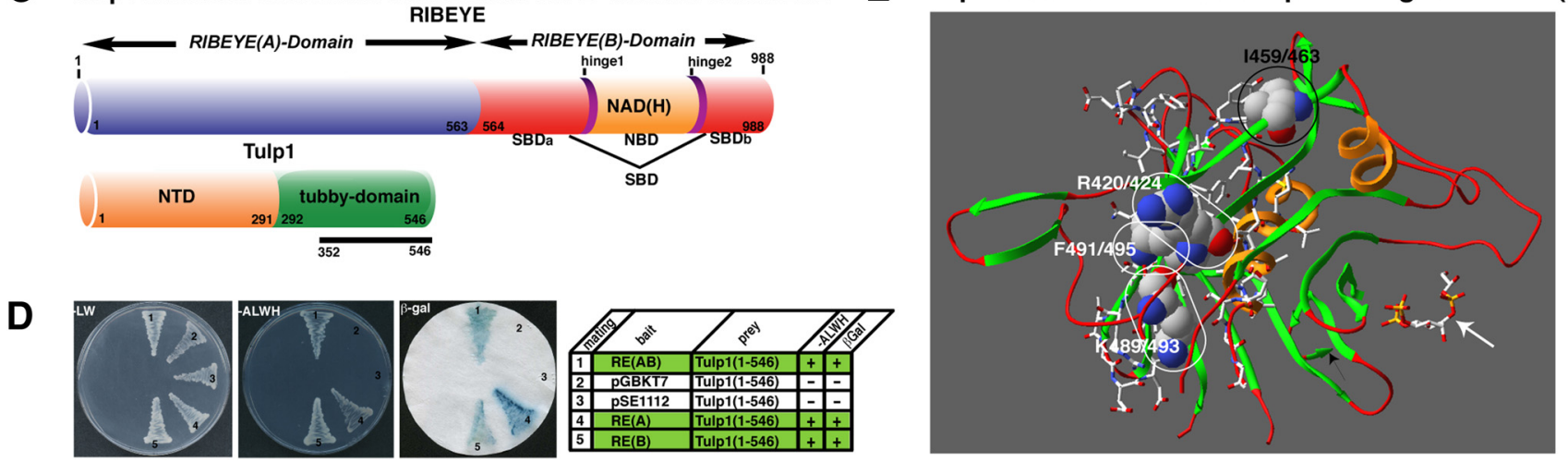

Figure 10. A, RIBEYE is coimmunoprecipitated by monoclonal antibodies against Tulp1. Mouse monoclonal antibodies against Tulp1 (5G2-4) were used to immunoprecipitate Tulp1 from the bovine retina ( $\boldsymbol{A} \boldsymbol{b}$, lane 1). Irrelevant mouse immunoglobulins or empty beads served as controls. In the controls, no Tulp1 was immunoprecipitated (Ab, lanes 2 and 3 ). A large amount of RIBEYE coimmunoprecipitated with Tulp1 antibodies ( $\boldsymbol{A a}$, lane 1 ) but not with control antibodies ( $\boldsymbol{A} \boldsymbol{a}$, lanes 2 and 3 ), indicating that Tulp1 exists in a common protein complex with RIBEYE in the bovine retina. $\boldsymbol{A} \boldsymbol{c}$, Control incubation in which the same blot as in $\boldsymbol{A} \boldsymbol{a}$ and $\boldsymbol{A} \boldsymbol{b}$ was stripped and reprobed with antibodies against tubulin (representative example from a total of five experiments). $\boldsymbol{B}$, Tulp 1 is present in synaptic ribbon complexes (lane 1) purified from photoreceptor synapses (OPL, lane 2) as shown by Western blotting with anti-Tulp1 antibodies. (B is a representative example from $n=$ 4 experiments.) C, Schematic domain structure of RIBEYE and Tulp1. RIBEYE consists of the A domain and the carboxy terminal B domain. SBD, bipartite substrate-binding domain of RIBEYE(B). NTD, N-terminal domain of Tulp1. The originally obtained Tulp1 prey clone covers amino acids 352-546 of bovine Tulp1 (solid bar). D, Tulp1 interacts with both RIBEYE(A) and RIBEYE(B) domains. Summary plates of YTH analyses. Interacting experimental bait-prey pairs are underlayered in green in the table (control matings are noncolored), $n=4$ experiments. $E$, Summary of structureguided mutagenesis studies. Analyzed disease mutants in the YTH system (see also Fig. 13) are depicted in the structure model of bovine Tulp1 tubby domain (based on the structure of human Tulp1 tubby domain (pdb3C5N; pdb3FIM) (Busam et al., unpublished observations; Gräslund et al., 2008). Amino acids that disrupt binding of RIBEYE(B) are depicted in a space-filling model (R420/424; K489/493; F491/495; white numbering). The first number indicates the amino acid number in human Tulp1; the second number indicates the corresponding position in bovine Tulp1. Disease mutants that disrupt binding to RIBEYE(B) are located next to each other opposite the phospholipid-binding interface of the tubby domain of Tulp1. Encircled in black is Isoleucine $1459 / 463$ at the homo-dimerization interface of Tulp1 that is not critical for Tulp1-RIBEYE interaction (Fig. 13). The carboxy terminal 44 amino acids lacking in a splice site mutation of Tulp1 (Banerjee et al., 1998) are depicted with side chains. White arrow points to the PIP 2 -binding site of Tulp1 (pdb1C8Z cocrystallized with IP3).

\section{Direct interaction between RIBEYE and Tulp1}

We identified a direct interaction between RIBEYE and Tulp1 in the YTH system. In a YTH screen, using the B domain of bovine RIBEYE as bait, we obtained Tulp1 as a prey clone (preyTulp1051) (see Fig. 13A, mating \#1; see also Fig. 10C,D). The original Tulp1 prey clone encoded for a large portion of the tubby domain of bovine Tulp1 (amino acids 352-546). We also verified that the entire tubby domain of Tulp1 interacts with RIBEYE(B) in the YTH system as judged by growth of the respective yeasts on -ALWH selective plates and expression of $\beta$-galactosidase activity (see Fig. 13A; mating \#4; see also Fig. $10 C, D)$. Also, full-length RIBEYE, which contains both A domain and $\mathrm{B}$ domain, interacted with the tubby domain of Tulp1 in the YTH system (Fig. 10C,D; see also Fig. 13), demonstrating that the A domain of RIBEYE does not prevent interaction of RIBEYE(B) with Tulp1. In contrast, Tulp1-expressing yeasts that were mated with full-length RIBEYE were even growing faster on selective medium (-ALWH) than Tulp1 yeasts that were mated with RIBEYE(B) domain only (data not shown). Therefore, we tested whether RIBEYE(A) domain also interacts with Tulp1 and con- 

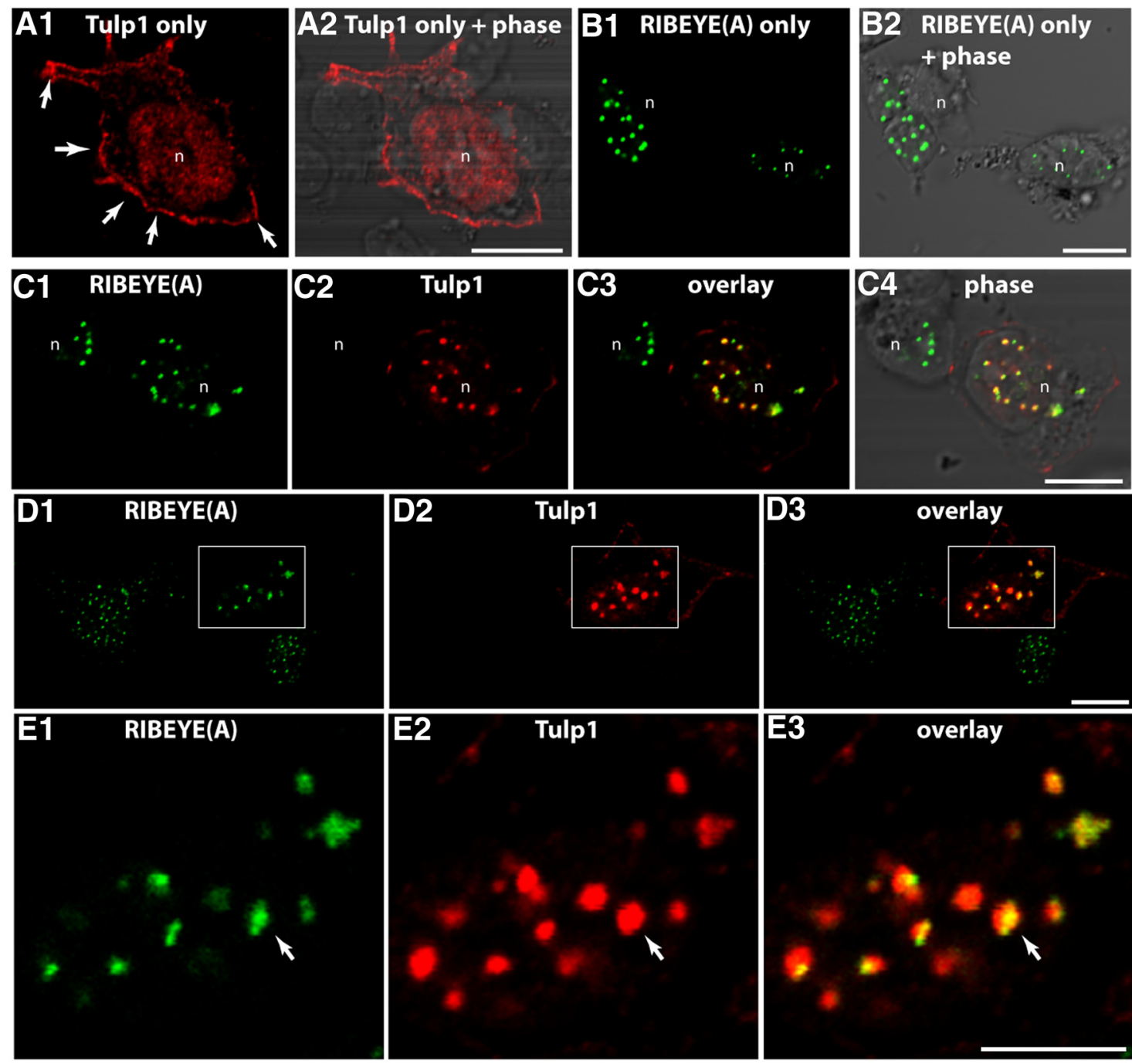

Figure 11. HEK293T cell transfected with the indicated expression plasmids. If HA-tagged Tulp1 was transfected alone $(\boldsymbol{A})$, we observed an enrichment of Tulp1 at the plasma membrane (A1, arrows). If myc-tagged RIBEYE(A) was transfected alone (B), we observed the previously described punctate, spot-like distribution in the cytosol (see also Schmitz et al., 2000; Magupalli et al., 2008) $(\boldsymbol{B} 1, \boldsymbol{B} 2)$. In contrast, if cells were cotransfected with both Tulp1 and RIBEYE(A) $(\boldsymbol{C}-\boldsymbol{E})$, Tulp1 was recruited to the RIBEYE(A) puncta in the cytosol $(\boldsymbol{E}$, arrow). $\boldsymbol{D}$, Boxed area is magnified in $\boldsymbol{E}$. $n=4$ experiments. $n$, nucleus of a transfected HEK293T cell. Scale bars, $\boldsymbol{A}-\boldsymbol{E}, 5 \mu \mathrm{m}$.

firmed this assumption in the YTH system (Fig. 10C,D, mating \#4). We observed a robust growth of the respectively mated yeasts on -ALWH selective medium and expression of $\beta$-galactosidase marker gene activity (Fig. 10D; see also Fig. 13). Thus, also the A domain of RIBEYE interacts with the tubby domain of Tulp1, supporting the assumption that two binding sites for Tulp1 are present in RIBEYE: one binding site located in the A domain and the second binding site located in the B domain of RIBEYE (Fig. 10C).

RIBEYE(B) consists of an NBD and the SBD (Alpadi et al., 2008; Magupalli et al., 2008; Schwarz et al., 2011). YTH analyses demonstrated that the NBD of $\operatorname{RIBEYE}(B)$ interacts with the tubby domain of Tulp1 (see Fig. 13B, mating \#1), whereas the SBD of RIBEYE(B) did not (see Fig. 13B, mating \#2). Lack of SBD-Tulp1 interaction is not due to misfolding of the SBD construct because the same SBD construct interacts with bassoon (Dembla et al., 2014), a binding partner of the SBD (tom Dieck et al., 2005). We also mapped the interaction between RIBEYE(A) and Tulp1 with the YTH system (see Fig. 13C). YTH analyses performed with N-terminal truncated RIBEYE(A) constructs (Magupalli et al., 2008) demonstrated that the shortest, minimal interacting region was contained in the carboxy terminal region ranging from amino acids 364-563 (see Fig. 13C, matings \#1-5). An even smaller amino terminal truncation, amino acids 438563, the "A2-interaction region" (Magupalli et al., 2008), did no longer interact with Tulp1 (see Fig. 13C, mating \#6). The lack of interaction between "A2" of RIBEYE(A) and Tulp1 was not due to inactivity or malfunction of A2 because the same construct strongly interacts with RIBEYE(A) (Magupalli et al., 2008). From these findings, we conclude that the region between amino acids 364-438 contains an important region for Tulp1 interaction (denoted as "TIR," Tulp1-interacting region of $\operatorname{RBBEYE}(\mathrm{A})$ in the schematic drawing in Fig. 13E).

\section{RIBEYE interacts with Tulp1 in cotransfected cells}

The direct RIBEYE-Tulp1 interaction identified in the YTH screen was further analyzed by other assays. For this purpose, we performed cotransfection experiments in HEK293T cells (Fig. 9). In transfected HEK293T cells, heterologous expression of RIBEYE(A) alone produced the well-known punctate immunolabeling pattern (see also Schmitz et al., 2000; Magupalli et al., 2008) (Fig. 11), whereas Tulp1 alone was enriched at the plasma 

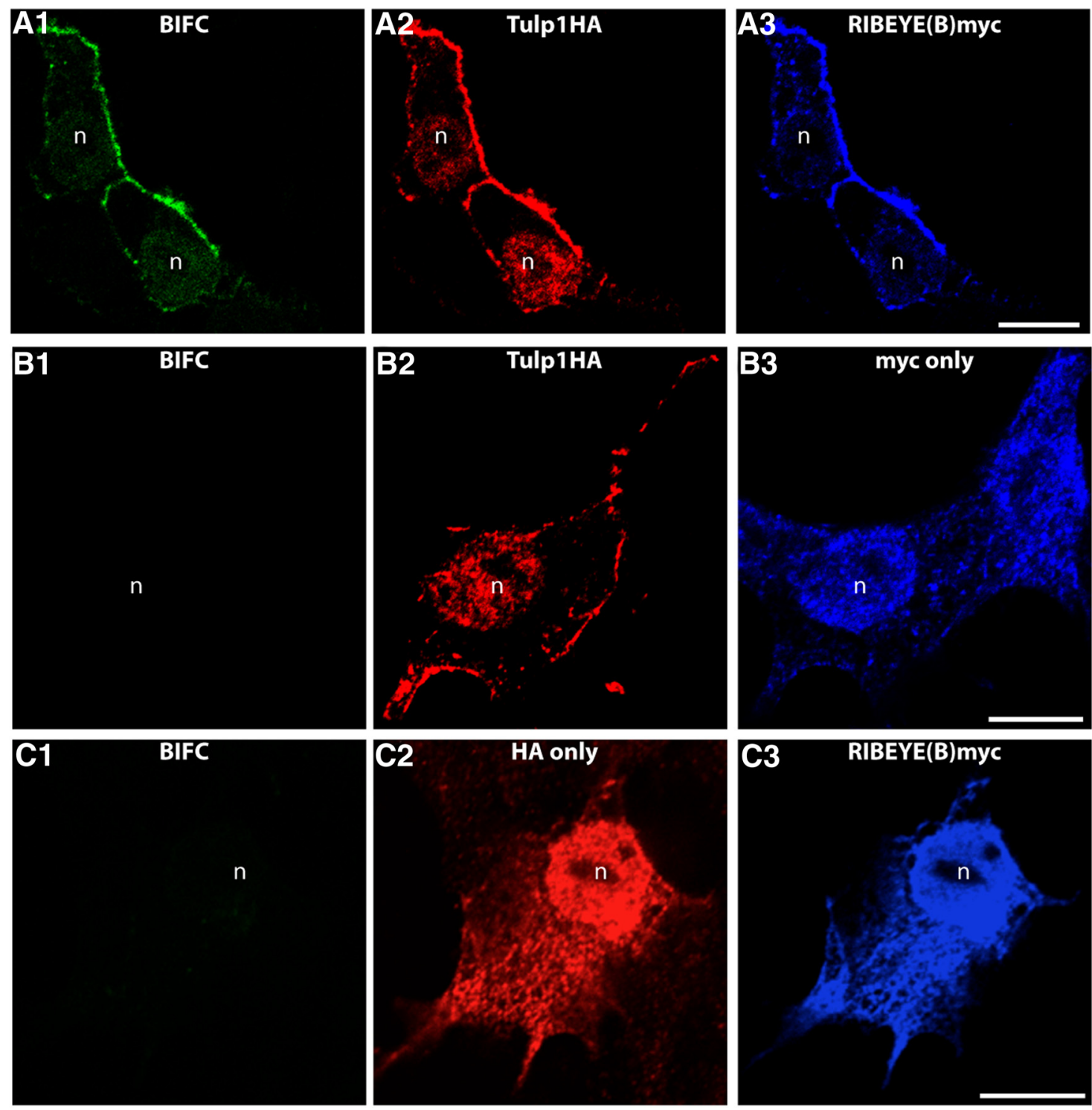

Figure 12. The indicated BIFC constructs were transfected into HEK293T cells and analyzed for fluorescence complementation (BIFC signal) in the green channel (mVenus). Expression of the separate plasmids was verified by immunolabeling with antibodies against the HA-tag (red channel) and with antibodies against myc-tag (far red channel, blue), exactly as previously described (Ritter et al., 2011). Fluorescence complementation was only observed if Tulp1 was cotransfected with RIBEYE(B) (A). Only in this case, we observed a BIFC signal (A1). If Tulp1 was transfected with empty control vectors (B), no fluorescence complementation was observed (B1). Similarly, if RIBEYE(B) was transfected with empty control plasmid $(\boldsymbol{C})$, no BIFC signal was generated (C1). $n=4$ experiments. $n$, nucleus of a transfected HEK293T cell. Scale bars, $\boldsymbol{A}-\boldsymbol{C}, 5 \mu \mathrm{m}$.

membrane (Fig. 11A), as previously described (Boggon et al., 1999; Santagata et al., 2001). In contrast, when Tulp1 and RIBE$\mathrm{YE}(\mathrm{A})$ were cotransfected and expressed in the same cell, Tulp1 was recruited to the RIBEYE(A)-typical, spot-like distribution, indicating direct interaction between Tulp1 and RIBEYE(A) (Fig. $11 C-E)$. To further analyze the interaction of RIBEYE(B) with Tulp1, we performed BIFCs (Fig. 12). In the selected BIFC system (Ritter et al., 2011), the mVenus fluorophore is split into two separate parts which are nonfluorescent. Only if the two mVenus halves come close to each other as a consequence of direct interaction of the proteins to which they are fused, the fluorescence is reconstituted (Ritter et al., 2011). RIBEYE(B) cotransfected with HA-tag only gave no BIFC signal (Fig. 12C), similarly as Tulp1 HA transfected with myc-tag alone (Fig. 12B). In contrast, RIBEYE(B) domain generated a strong BIFC signal if cotransfected with Tulp1 and was recruited from a diffuse localization to a Tulp1 typical localization (Fig. 12A). In HEK293T cells, double- transfected with Tulp1 HA and RIBEYE(B)myc, a large portion of $\operatorname{RIBEYE}(\mathrm{B})$ was observed at the plasma membrane at sites where Tulp1 was also enriched.

\section{Disease mutants of Tulp1 disrupt interaction between Tulp1} and RIBEYE $(B)$

We tested whether well-known disease mutations of Tulp1 that cause retinitis pigmentosa RP14 affect the interaction of Tulp1 with $\operatorname{RIBEYE}(\mathrm{A})$ and $\mathrm{RIBEYE}(\mathrm{B})$ using the YTH system (Figs. $10 E, 13 D)$. We tested Tulp1(R424P, I463K, K493R, F495L) and a Tulp1 deletion construct that lacks the last 44 carboxy terminal amino acids of bovine Tulp1 (Banerjee et al., 1998; Hagstrom et al., 1998; Lewis et al., 1999). These mutants correspond to human disease mutants Tulp1(R420P, I459K, K489R, F491L) of human Tulp1 as well as to a splice site mutation of human Tulp1 that lacks amino acids 499-542 of human Tulp1 (corresponding to the last 44 amino acids of bovine Tulp1). These mutations lead to 


$\begin{array}{lllcc}\text { A Tulp1 interacts with RIBEYE(A)-domain and RIBEYE(B)-domain } \\ \text { mating } & \text { bait } & \text { prey } & \text { ALWH } & \text { B-gal } \\ 1 & \text { RE(B) } & \text { Tulp1(352-546) } & + & + \\ 2 & \text { RE(AB) } & \text { Tulp1(292-546) } & + & + \\ 3 & \text { RE(A) } & \text { Tulp1(292-546) } & + & + \\ 4 & \text { RE(B) } & \text { Tulp1(292-546) } & + & + \\ 5 & \text { RE(AB) } & \text { Tulp1(352-546) } & + & + \\ 6 & \text { RE(A) } & \text { Tulp1(352-546) } & + & +\end{array}$
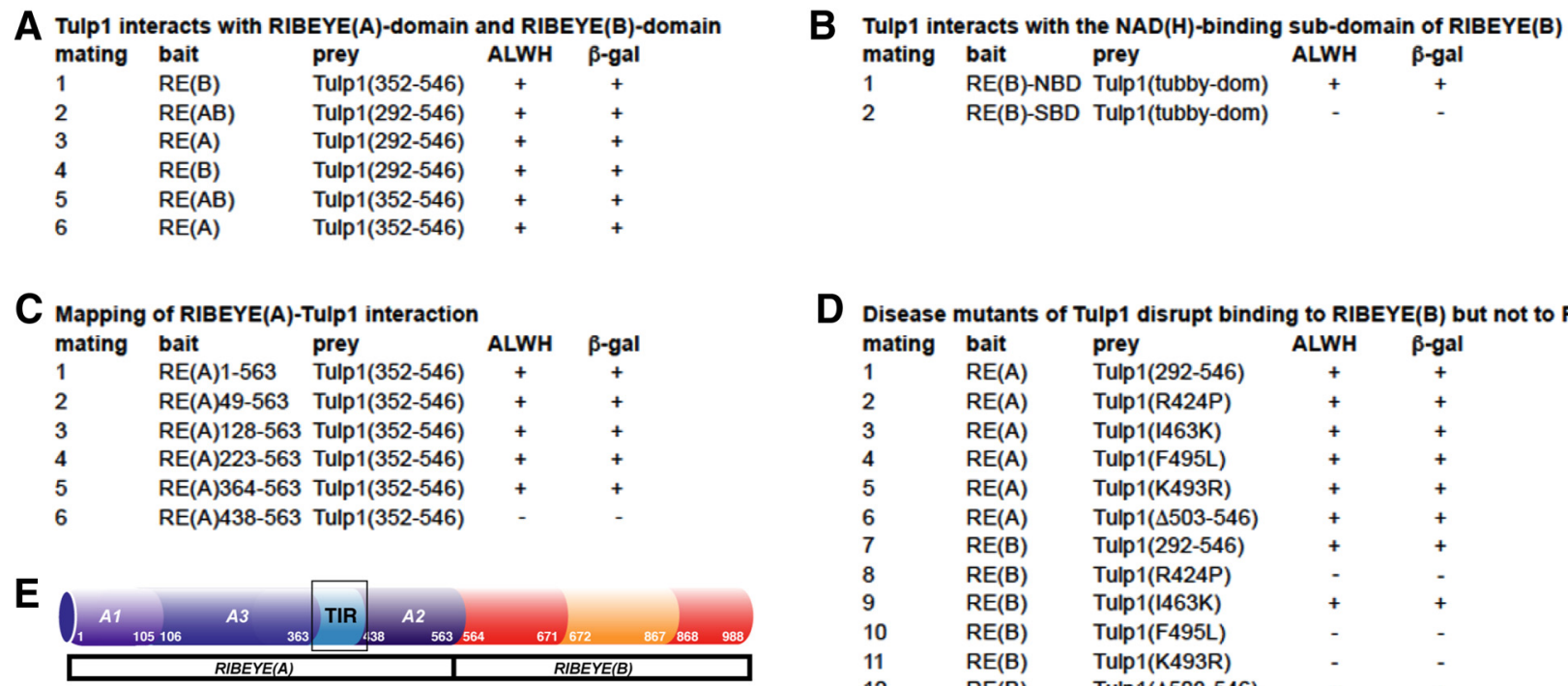

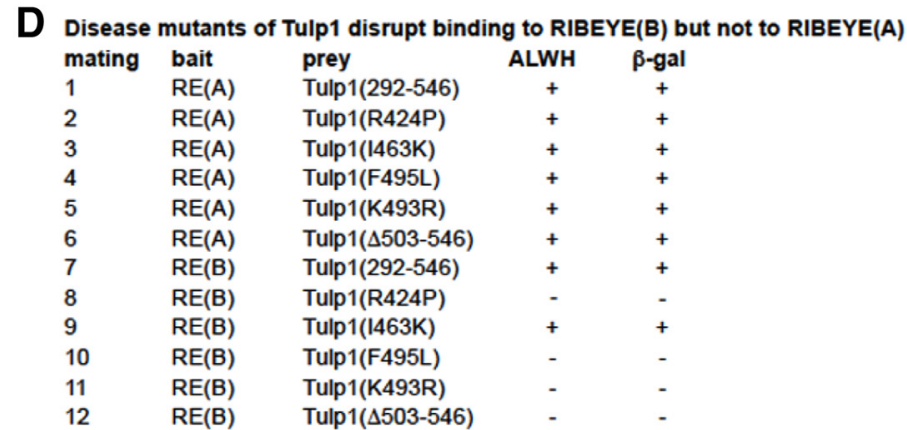

Figure 13. $A-D$, Summary of experimental bait/prey YTH mating pairs. Growth on -ALWH selective plates and expression of $\beta$-galcatosidase ( $\beta$-gal) activity indicates interaction in the YTH system. For all bait and preys, auto-activation controls were performed, which are not demonstrated in the table due to limitations in space. All bait constructs and all prey constructs were verified for auto-activation by mating with the respective empty prey/bait constructs (pGBKT7, pACT2) and irrelevant bait/prey constructs (pSE1111 and pSE1112), as previously published (Alpadi et al., 2008; Magupalli et al., 2008; Venkatesan et al., 2010; Dembla et al., 2014). None of the bait or prey constructs listed was auto-activating. $\boldsymbol{E}$, Schematic drawing indicates the localization of the Tulp1-interacting region (TIR) in $\operatorname{RIBEYE}(\mathrm{A})$.

early-onset, severe RP in humans (Banerjee et al., 1998; Gu et al., 1998; Hagstrom et al., 1998; Lewis et al., 1999; Paloma et al., 2000). Except for Tulp1(I463K), all of the disease relevant mutants tested abolished interaction of Tulp1 with RIBEYE(B), but not with RIBEYE(A) (Fig. 13).

\section{Discussion}

Mutations in the Tulp1 gene are associated with severe, earlyonset photoreceptor degeneration with rapid progression and severe vision impairment. Therefore, Tulp1 is clearly required for normal vision. But the functional role of Tulp1 in the retina, where it is exclusively expressed in photoreceptors, is only incompletely understood.

In the present study, we demonstrated that Tulp1 is highly enriched in the periactive zone of photoreceptor synapses in the bovine retina. The periactive zone of photoreceptor synapses contains major endocytic proteins and is a hotspot of endocytic activity (Wahl et al., 2013; Dembla et al., 2014). In agreement with these findings, we found a close correlation between Tulp1 and endocytic proteins (e.g., dynamin, clathrin heavy chain) at photoreceptor periactive zones using SR-SIM. In agreement with these findings, we also found $\mathrm{PIP}_{2}$ enriched in the periactive zone. The localization of $\mathrm{PIP}_{2}$ in the periactive zone makes sense for at least two reasons: (1) Tulp1 is a $\mathrm{PIP}_{2}$-binding protein (Boggon et al., 1999; Santagata et al., 2001); and (2) PIP $_{2}$ is a well-known signaling lipid important for initiating endocytosis (Di Paolo et al., 2004; Wenk and De Camilli, 2004; Posor et al., 2015). Furthermore, a key enzyme for the synthesis of $\mathrm{PIP}_{2}$ has been recently described to be enriched also at that site (Sakagami et al., 2014).

In the present study, we demonstrated that Tulp1 is essential for the structural and functional integrity of the endocytic machinery in the periactive zone of photoreceptor synapses. In Tulp1 knock-out mice, periactive endocytic proteins disappeared from the periactive zone. In contrast to the severely mislocalized endocytic proteins in the periactive zone, active zone proteins (i.e., Rim proteins and voltage-gated calcium channels) remained unchanged in their distribution, stressing the specificity of the observed changes in the periactive zone. Also at the functional level, periactive zone endocytosis was severely altered. In wildtype littermate controls, uptake of extracellular tracers was particularly strong in the periactive zone (Wahl et al., 2013; Dembla et al., 2014) as previously shown). Control experiments with dynamin inhibitors (dynasore) that strongly reduced the signal intensities of the endocytic tracers (SR101, FM1-43) close to the synaptic ribbon both in retinal slices (Fig. 7) and isolated photoreceptors (Fig. 8) support the proposal that the fluorescence signals in the uptake assay are mainly resulting from a dynamindependent endocytic uptake of the fluorescent tracers at the periactive zone. In contrast to the wild-type, in Tulp1 knock-out mice, periactive zone endocytosis was completely abolished concomitant with the described loss of endocytic proteins at that site.

From these findings, we conclude that Tulp1 has at least two important functions in photoreceptor presynaptic terminals. The first function is promoting endocytic membrane retrieval. This proposal is based on our finding that endocytic tracer uptake was strongly reduced in photoreceptor terminals of Tulp1 knock-out mice compared with littermate control mice. Identical results were obtained with different endocytic tracers (FM1-43; SR101) and different experimental systems (isolated photoreceptors and retinal slices). A role in endocytosis is also supported by previous findings that demonstrated Tulp1 being present in retinal protein complexes that contain dynamin-1 (Xi et al., 2007; Grossman et al., 2013). Dynamin-1 is the mechanoenzyme that mediates periactive zone endocytosis (Wahl et al., 2013; Dembla et al., 2014). Interestingly, Drosophila king tubby, a member of the tubby family, is involved in the endocytosis of rhodopsin in the rhabdomere microvilli of fly photoreceptors (Chen et al., 2012), supporting also a more general role of tubby family proteins in endocytic membrane trafficking.

This study also revealed a second function of Tulp1. In addition to promoting endocytosis in the photoreceptor presynaptic terminal, an additional function of Tulp1 is the recruitment of the endocytic protein machinery to the periactive 
zone close to the synaptic ribbon. This was shown by SR-SIM immunolabeling analyses that demonstrated a loss of major endocytic proteins (dynamin, clathrin heavy chain) in the periactive zone of Tulp1 knock-out mice but not in littermate control mice. The association of the periactive zone endocytic machinery with the synaptic ribbon complex will help to coordinate exocytosis of synaptic vesicles at the active zone at the base of the ribbon with compensatory endocytosis in the periactive zone. Disruption of this link, as in the case of the Tulp1 knock-out mice, would consequently lead to a loss of endocytic proteins from the periactive zone. This is exactly what we observed in the Tulp1 knock-out mice.

A possible explanation for the recruitment of the endocytic machinery to the periactive zone is given by the interaction of Tulp1 with RIBEYE, the main structural component of synaptic ribbons. RIBEYE-Tulp1 interaction was shown by various independent approaches. In agreement with these observations, we observed a strong synaptic ribbon phenotype in the Tulp1 knockout mouse. Synaptic ribbon numbers in Tulp1 knock-out mice were normal compared with littermate control mice at early stages of postnatal development (i.e., postnatal day 16 [P16]). But instead of increasing in number in the course of postnatal maturation of photoreceptor synapses, photoreceptor synaptic ribbon numbers in Tulp1 knock-out mice even strongly decreased at more advanced stages of synaptic maturation (P30) (Fig. 9I). This indicates that the function of Tulp1 is particularly required in more mature photoreceptor synapses (i.e., after eye opening when photoreceptor synapses start to communicate the lighttriggered information to the inner retina).

Our data also indicate that endocytic membrane retrieval is important for the stability of the synaptic ribbon because the strong decay in the number of photoreceptor synaptic ribbon occurred shortly after the loss of endocytic membrane retrieval at P16. In line with our findings are observations from the zebrafish nrc mutants. In nrc zebrafish mutants, loss of the endocytic protein synaptojanin also leads to structural defects of the synaptic ribbon (Van Epps et al., 2004).

The clinical importance of identified RIBEYE-Tulp1 interaction is emphasized by our observations that the structure-guided Tulp1 point mutants, which disrupt binding between RIBEYE(B) and Tulp1, are causing RP in human patients (Daiger et al., 2007). Our data provide a novel framework for the synaptic changes observed in ERG analyses of Tulp1 knock-out mice and RP14 patients (Hagstrom et al., 1998; den Hollander et al., 2008; Grossman et al., 2009). Previous studies showed that some RP mutant rhodopsins have defects in endocytic retrieval (Chuang et al., 2004) and rhodopsin is mislocalized in Tulp1-knock-out mice (Hagstrom et al., 2001; Grossman et al., 2011). Our current findings propose that, in addition to the rhodopsin mistargeting, these synaptic changes in Tulp1 knock-out mice may also importantly contribute to RP.

The synaptic changes in Tulp1 knock-out mice affect the synaptic ribbon complex and ribbon-associated functions and proteins. In the present study, we focused mainly on changes in endocytosis at the ribbon complex for several reasons: (1) In Tulp1 knock-out mice, we observed a strong decrease in the recruitment of endocytic proteins to the periactive zone of photoreceptor ribbon synapses, whereas active zone proteins (Cav1.4; RIM1/2) remained unchanged. (2) Uptake of fluorescent tracers is strongly reduced in Tulp 1 knock-out mice. This fluorescence uptake (e.g., of FM1-43 and SR101) close to the synaptic ribbon appears to be based predominantly on dynamin-dependent endocytosis as judged by control experi- ments with inhibitors of dynamin inhibitors (dynasore). Inhibitors of dynamin strongly inhibit the uptake of the fluorescent tracers close to the synaptic ribbon in wild-type retinas. Clearly, in addition to endocytosis, deletion of Tulp1 could also affect other synaptic processes (e.g., changes in exocytosis or vesicle trafficking/vesicle recruitment). This possibility is based on the previously described changes of bassoon and piccolo in Tulp1 knock-out mice (Grossman et al., 2009). In addition to endocytosis (Fenster et al., 2003), defects in the piccolo-/basson-system (Dick et al., 2003; tom Dieck et al., 2005; Grossman et al., 2009; Frank et al., 2010; Hallermann et al., 2010; Regus-Leidig et al., 2013) could also lead to changes in exocytosis and in the function of the active zone. These possibilities need to be further addressed in future studies.

Our findings propose that synaptic changes in Tulp1 knock-out mice and Tulp1-based RP14 patients are the result of an impaired periactive zone endocytosis in photoreceptor synapses. In photoreceptor outer segments, defects in endocytic retrieval of rhodopsin can underlie RP (Chuang et al., 2004). Our data reveal that impaired endocytosis at the photoreceptor synapse could similarly contribute to RP. We propose that Tulp1-dependent periactive zone endocytosis in photoreceptor terminals is essential to keep photoreceptor synapses functionally alive to continuously communicate the light-triggered information to the inner retina for further processing. The current findings suggest a new model for Tulp1mediated localization of the endocytic machinery at the periactive zone of ribbon synapses and offer a new rationale and mechanism for vision loss associated with genetic defects in Tulp1.

\section{References}

Alpadi K, Magupalli VG, Käppel S, Köblitz L, Schwarz K, Seigel GM, Sung CH, Schmitz F (2008) RIBEYE recruits Munc119, the mammalian ortholog of the Caenorhabditis elegans protein unc119, to synaptic ribbons of photoreceptor synapses. J Biol Chem 283:26461-26467. CrossRef Medline

Anjum R, Ayoubian H, Schmitz F (2014) Differential synaptic distribution of the scaffold proteins Cask and caskinl in the bovine retina. Mol Cell Neurosci 62:19-29. CrossRef Medline

Banerjee P, Kleyn PW, Knowles JA, Lewis CA, Ross BM, Parano E, Kovats SG, Lee JJ, Penchaszadeh GK, Ott J, Jacobson SG, Gilliam TC (1998) Tulp1 mutation in two extended Dominican kindreds with autosomal recessive retinitis pigmentosa. Nat Genet 18:177-179. CrossRef Medline

Boggon TJ, Shan WS, Santagata S, Myers SC, Shapiro L (1999) Implication of tubby proteins as transcription factors by structure-based functional analysis. Science 286:2119-2125. CrossRef Medline

Buckley K, Kelly RB (1985) Identification of a transmembrane glycoprotein specific for secretory vesicles of neural and endocrine cells. J Cell Biol 100:1284-1294. CrossRef Medline

Carroll K, Gomez C, Shapiro L (2004) Tubby proteins: the plot thickens. Nat Rev Mol Cell Biol 5:55-63. CrossRef Medline

Chen SF, Tsai YC, Fan SS (2012) Drosophila king tubby (ktub) mediates light-induced rhodopsin endocytosis and retinal degeneration. J Biomed Sci 19:101. CrossRef Medline

Chuang JZ, Vega C, Jun W, Sung CH (2004) Structural and functional impairment of endocytic pathways by retinitis pigmentosa mutant rhodopsin-arrestin complexes. J Clin Invest 114:131-140. CrossRef Medline

Costes SV, Daelemans D, Cho EH, Dobbin Z, Pavlakis G, Lockett S (2004) Automatic and quantitative measurement of protein-protein colocalization in live cells. Biophys J 26:3993-4003. CrossRef Medline

Daiger SP, Bowne SJ, Sullivan LS (2007) Perspectives on genes and mutations causing retinitis pigmentosa. Arch Ophthalmol 125:151-158. CrossRef Medline

Dembla M, Wahl S, Katiyar R, Schmitz F (2014) ArfGAP3 is a component of the photoreceptor synaptic ribbon complex and forms a $\mathrm{NAD}(\mathrm{H})$ - 
regulated, redox-sensitive complex with RIBEYE that is important for endocytosis. J Neurosci 34:5245-5260. CrossRef Medline

den Hollander AI, Lopez I, Yzer S, Zonneveld MN, Janssen IM, Strom TM, Hekir-Kwa JY, Veltman JA, Arends ML, Meitinger T, Musarella MA, van den Born LI, Fishman GA, Maumensee IH, Rohrschneider K, Cremers FP, Koenekoop RK (2007) Identification of novel mutations in patients with Leber Congenital Amaurosis and juvenile RP by genome-wide homozygosity mapping with SNP microarrays. Invest Ophthalmol Vis Sci 48:5690-5698. CrossRef Medline

den Hollander AI, Roepman R, Koenekoop RK, Cremers FP (2008) Leber congenital amaurosis: genes, proteins and disease mechanisms. Prog Ret Eye Res 27:391-419. CrossRef Medline

Dick O, tom Dieck S, Altrock WD, Ammermüller J, Weiler R, Garner CC, Gundelfinger ED, Brandstätter JH (2003) The presynaptic active zone protein bassoon is essential for photoreceptor ribbon synapse formation in the retina. Neuron 37:775-786. CrossRef Medline

Di Paolo G, Moskowitz HS, Gipson K, Wenk MR, Voronov S, Obayashi M, Flavell R, Fitzsimonds RM, Ryan TA, De Camilli P (2004) Impaired PtdIns(4,5)P2 synthesis in nerve terminals produces defects in synaptic vesicle trafficking. Nature 431:415-422. CrossRef Medline

Dunn KW, Kamocka MM, McDonald JH (2011) A practical guide to evaluate colocalization in biological microscopy. Am J Physiol Cell Physiol 300:C723-C742. CrossRef Medline

Fenster SD, Kessels MM, Qualmann B, Chung WJ, Nash J, Gundelfinger ED, Garner CC (2003) Interactions between piccolo and the actin/dynaminbinding protein Abp1 link vesicle endocytosis to presynaptic active zones. J Biol Chem 278:20268-20277. CrossRef Medline

Frank T, Rutherford MA, Strenzke N, Neef A, Pangršiè T, Khimich D, Fejtova A, Gundelfinger ED, Liberman MC, Harke B, Bryan KE, Lee A, Egner A, Riedel D, Moser T (2010) Bassoon and the synaptic ribbon organize $\mathrm{Ca}^{2+}$ channels and vesicles to add release sites and promote refilling. Neuron 68:724-738. CrossRef Medline

Grabner CP, Gandini MA, Rehak R, Le Y, Zamponi GW, Schmitz F (2015) RIM1/2-mediated facilitation of Cav1.4 channel opening is required for $\mathrm{Ca}^{2+}$-stimulated release in mouse rod photoreceptor synapses. J Neurosci 35:13133-13147. CrossRef Medline

Gräslund S, Sagemark J, Berglund H, Dahlgren LG, Flores A, Hammarström M, Johansson I, Kotenyova T, Nilsson M, Nordlund P, Weigelt J (2008) The use of systematic $\mathrm{N}$ - and $\mathrm{C}$-terminal deletions to promote production and structural studies of recombinant protein. Protein Expr Purif 58: 210-221. CrossRef Medline

Gray EG, Pease HL (1971) On understanding the organization of the retinal receptor synapses. Brain Res 35:1-15. CrossRef Medline

Grossman GH, Pauer GJ, Narendra U, Peachey NS, Hagstrom SA (2009) Early synaptic defects in Tulp1 -/- mice. Invest Ophthalmol Vis Sci 50:3074-3083. CrossRef Medline

Grossman GH, Watson RF, Pauer GJ, Bollinger K, Hagstrom SA (2011) Immunocytochemical evidence of Tulp1-dependent outer segment protein transport pathways in photoreceptor cells. Exp Eye Res 93:658-668. CrossRef Medline

Grossman GH, Ebke LA, Beight CD, Jang GF, Crabb JW, Hagstrom SA (2013) Protein partners of dynamin-1 in the retina. Vis Neurosci 30: 129-139. CrossRef Medline

Gu S, Lennon A, Li Y, Lorenz B, Fossarello M, North M, Gal A, Wright A (1998) Tubby-like protein-1 mutations in autosomal recessive retinitis pigmentosa. Lancet 351:1103-1104. CrossRef Medline

Hagstrom SA, North MA, Nishina PL, Berson EL, Dryja TP (1998) Recessive mutations in the gene encoding for the tubby-like protein Tulp1 in patients with retinitis pigmentosa. Nat Genet 18:174-176. CrossRef Medline

Hagstrom SA, Adamian M, Scimeca M, Pawlyk BS, Yue G, Li T (2001) A role for the Tubby-like protein 1 in rhodopsin transport. Invest Ophthalmol Vis Sci 42:1955-1962. Medline

Hallermann S, Fejtova A, Schmidt H, Weyhersmüller A, Silver RA, Gundelfinger ED, Eilers J (2010) Bassoon speeds vesicle reloading at a central excitatory synapse. Neuron 68:710-723. CrossRef Medline

Hanein S, Perrault I, Gerber S, Tanguy G, Barbet F, Ducroq D, Calvas P, Dollfus H, Hamel C, Lopponen T, Munier F, Santos L, Shalev S, Zafeiriou D, Dufier JL, Munnich A, Rozet JM, Kaplan J (2004) Leber congenital amaurosis: comprehensive survey of the genetic heterogeneity, refinement of the clinical definition, and genotype-phenotype correlations as a strategy for molecular diagnosis. Hum Mutat 23:306-317. CrossRef Medline

Ikeda A, Nishina PM, Naggert JK (2002) The tubby-like proteins, a family with roles in neuronal development and function. J Cell Sci 115:9-14. Medline

Ikeda S, He W, Ikeda A, Naggert JK, North MA, Nishina PM (1999) Cellspecific expression of tubby gene family members (tub, Tulp1,2, and 3 ) in the retina. Invest Ophthalmol Vis Sci 40:2706-2712. Medline

Kikuchi T, Arai J, Shibuki H,Kawashima H, Yoshimura N (2000) Tubbylike protein 1 as an autoantigen in cancer-associated retinopathy. J Neuroimmunol 103:26-33. CrossRef Medline

Lewis CA, Batlle IR, Batlle KG, Banerjee P, Cideciyan AV, Huang J, Alemán TS, Huang Y, Ott J, Gilliam TC, Knowles JA, Jacobson SG (1999) Tubby-like protein 1 homozygous splice site mutation causes early-onset severe retinal degeneration. Invest Ophthalmol Vis Sci 40:2106-2114. Medline

Magupalli VG, Schwarz K, Alpadi K, Natarajan S, Seigel GM, Schmitz F (2008) Multiple RIBEYE-RIBEYE interactions create a dynamic scaffold for the formation of synaptic ribbons. J Neurosci 28:7954-7967. CrossRef Medline

Matthews G, Fuchs P (2010) The diverse roles of ribbon synapses in sensory neurotransmission. Nat Rev Neurosci 11:812-822. CrossRef Medline

Milam AH, Hendrickson AE, Xiao M, Smith JE, Possin DE, John SK, Nishina PM (2000) Localization of Tubby-like protein 1 in developing and human retinas. Invest Opthalmol Vis Sci 41:2352-2356. Medline

Mukhopadhyay S, Jackson PK (2011) The tubby family proteins. Genome Biol 12:225. CrossRef Medline

Paloma E, Hjelmqvist L, Bayés M, García-Sandoval B, Ayuso C, Balcells S, Gonzàlez-Duarte R (2000) Novel mutations in the TULP1 Gene causing autosomal recessive retinitis pigmentosa. Invest Ophthalmol Vis Sci 41: 656-659. Medline

Pelassa I, Zhao C, Pasche M, Odermatt B, Lagnado L (2014) Synaptic vesicles are "primed" for fast clathrin-mediated endocytosis at the ribbon synapse. Front Mol Neurosci 7:91. CrossRef Medline

Posor Y, Eichhorn-Grünig M, Haucke V (2015) Phosphoinositides in endocytosis. Biochim Biophys Acta 1851:794-804. CrossRef Medline

Rea R, Li J, Dharia A, Levitan ES, Sterling P, Kramer RH (2004) Streamlined synaptic vesicle cycle in cone photoreceptor terminals. Neuron 41:755-766. CrossRef Medline

Regus-Leidig H, tom Dieck S, Specht D, Meyer L, Brandstätter JH (2009) Early steps in the assembly of photoreceptor ribbon synapses in the mouse retina: the involvement of precursor spheres. J Comp Neurol 512:814-824. CrossRef Medline

Regus-Leidig H, Ott C, Löhner M, Atorf J, Fuchs M, Sedmak T, Kremers J, Fejtová A, Gundelfinger ED, Brandstätter JH (2013) Identification and immunocytochemical characterization of piccolino, a novel piccolo splice variant selectively expressed at sensory ribbon synapses of the eye and ear. PLoS One 8:e70373. CrossRef Medline

Ribic A, Liu X, Crair MC, Biederer T (2014) Structural organization and function of mouse photoreceptor ribbon synapses involve the immunoglobulin adhesion protein syncam1. J Comp Neurol 522:900-920. CrossRef Medline

Ritter LM, Khattree N, Tam B, Moritz OL, Schmitz F, Goldberg AF (2011) In situ visualization of protein interactions in sensory neurons: glutamic acid-rich proteins (GARPs) play differential roles for photoreceptor outer segment scaffolding. J Neurosci 31:11231-11243. CrossRef Medline

Sakagami H, Katsumata O, Hara Y, Tamaki H, Fukaya M (2014) Preferential localization of type I phosphatidylinositol 4-phosphate 5-kinase at the periactive zone of mouse photoreceptor synapses. Brain Res 1586:23-33. CrossRef Medline

Santagata S, Boggon TJ, Baird CL, Gomez CA, Zhao J, Shan WS, Myszka DG, Shapiro L (2001) G-protein signalling through tubby proteins. Science 292:2041-2050. CrossRef Medline

Schermelleh L, Heintzmann R, Leonhardt H (2010) A guide to superresolution fluorescence microscopy. J Cell Biol 190:165-175. CrossRef Medline

Schmitz F (2009) The making of synaptic ribbons: how they are built and what they do. Neuroscientist 15:611-624. CrossRef Medline

Schmitz F (2014) Presynaptic $\mathrm{Ca}^{2+}$ and GCAPs: aspects on the structure and function of photoreceptor ribbon synapses. Front Mol Neurosci 7:3. CrossRef Medline

Schmitz F, Königstorfer A, Südhof TC (2000) RIBEYE, a component of syn- 
aptic ribbons: a protein's journey through evolution provides insight into synaptic ribbon function. Neuron 28:857-872. CrossRef Medline

Schoch S, Mittelstaedt T, Kaeser PS, Padgett D, Feldmann N, Chevaleyre V, Castillo PE, Hammer RE, Han W, Schmitz F, Lin W, Südhof TC (2006) Redundant functions of RIM1alpha and RIM2alpha in $\mathrm{Ca}^{2+}$-triggered neurotransmitter release. EMBO J 25:5852-5863. CrossRef Medline

Schwarz K, Natarajan S, Kassas N, Vitale N, Schmitz F (2011) The synaptic ribbon is a site of phosphatidic acid generation in ribbon synapses. J Neurosci 31:15996-16011. CrossRef Medline

tom Dieck S, Altrock WD, Kessels MM, Qualmann B, Regus H, Brauner D, Fejtová A, Bracko O, Gundelfinger ED, Brandstätter JH (2005) Molecular dissection of the photoreceptor ribbon synapse: physical interaction of Bassoon and RIBEYE is essential for the assembly of the synaptic ribbon complex. J Cell Biol 168:825-836. CrossRef Medline

Van Epps HA, Hayashi M, Lucast L, Stearns GW, Hurley JB, De Camilli P, Brockerhoff SE (2004) The zebrafish nrc mutant reveals a role for the phosphoinositide phosphatase synaptojanin in cone photoreceptor ribbon anchoring. J Neurosci 24:8641-8650. CrossRef Medline
Venkatesan JK, Natarajan S, Schwarz K, Mayer SI, Alpadi K, Magupalli VG, Sung $\mathrm{CH}$, Schmitz F (2010) NAD(H)-dependent binding of the neuronal $\mathrm{Ca}^{2+}$-sensor protein GCAP2 to photoreceptor synaptic ribbons. J Neurosci 30:6559-6576. CrossRef Medline

Wahl S, Katiyar R, Schmitz F (2013) A local, periactive zone endocytic machinery at photoreceptor synapses in close vicinity to synaptic ribbons. J Neurosci 33:10278-10300. CrossRef Medline

Wang Y, Okamoto M, Schmitz F, Hofmann K, Südhof TC (1997) RIM is a putative Rab3 effector in regulating synaptic-vesicle fusion. Nature 388 : 593-598. CrossRef Medline

Wenk MR, De Camilli P (2004) Protein-lipid interactions and phosphinositide metabolism in membrane traffic: insights from membrane recycling in nerve terminals. Proc Natl Acad Sci U S A 101:8262-8269. CrossRef Medline

Xi Q, Pauer GJ, Ball SL, Rayborn M, Hollyfield JG, Peachey NS, Crabb JW, Hagstrom SA (2007) Interaction between the photoreceptor-specific tubby-like protein 1 and the neuronal-specific dynamin-1. Invest Ophthalmol Vis Sci 48:2837-2844. CrossRef Medline 